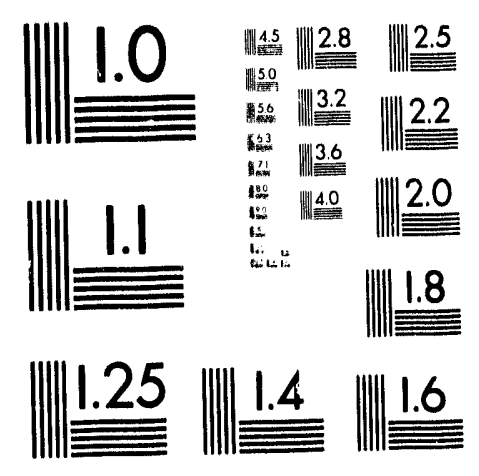



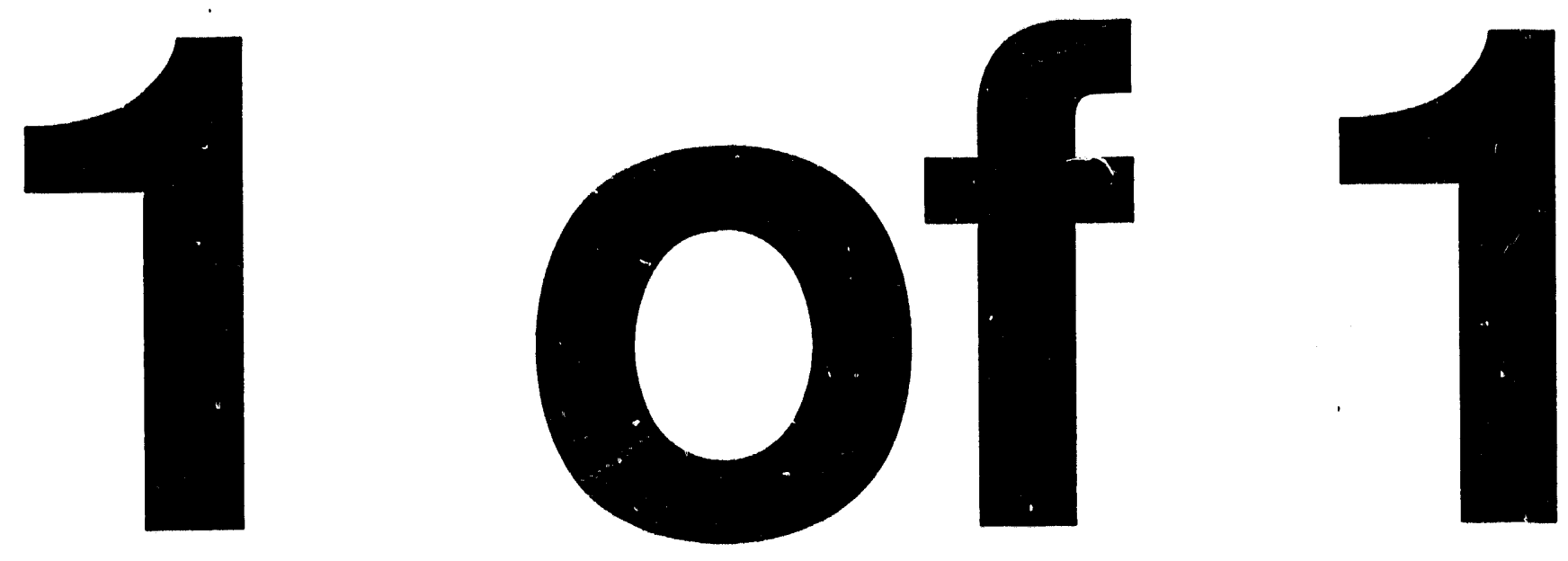
LBL-34412

UC- 920

\title{
ELECTRIC MOTOR SYSTEMS IN DEVELOPING COUNTRIES: OPPORTUNITIES FOR EFFICIENCY IMPROVEMENT
}

\author{
Stephen Meyers, Patricia Monahan, Piers Lewis, and Steve Greenberg \\ Energy Analysis Program \\ Energy and Environment Division \\ Lawrence Berkeley Laboratory \\ University of California \\ Berkeley, CA 94720
}

\section{Steven Nadel}

American Council for an Energy-Efficient Economy

Washington, D.C.

August 1993

This work was supported by the Office of Environmental Analysis, Office of Policy, Planning and Program Evaluation, U.S. Department of Energy through Contract No. DE-AC03-76SF00098. 


\begin{abstract}
This report presents an overview of the current status and efficiency improvement potential of industrial motor systems in developing countries. Better management of electri: motor systems is of particular relevance in developing countries, where improved efficiency can lead to increased productivity and slower growth in electricity demand. Motor systems currently consume some $65-80 \%$ of the industrial electricity in developing countries. Drawing on studies from Thailand, India, Brazil, China, Pakistan, and Costa Rica, we describe potential efficiency gains in various parts of the motor system, from the electricity delivery system through the motor to the point where useful work is performed. We report evidence of a significant electricity conservation potential. Most of the efficiency improvement methods we examine are very cost-effective from a societal viewpoint, but are generally not implemented due to various barriers that deter their adoption. Drawing on experiences in North America, we discuss a range of policies to overcome these barriers, including education, training, minimum efficiency standards, motor efficiency testing protocols, technical assistance programs, and financial incentives.
\end{abstract}




\section{TABLE OF CONTENTS}

EXECUTIVE SUMMARY $\ldots \ldots \ldots \ldots \ldots \ldots \ldots \ldots \ldots \ldots$ E-1

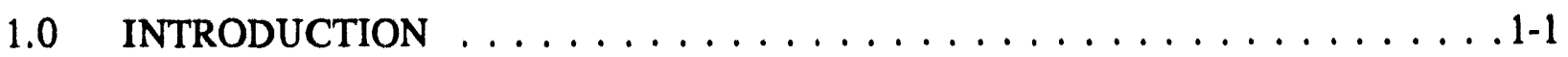

1.1 Conceptual Overview of Motor System Efficiency . . . . . . . . . 1-2

1.2 Estimating Electricity Savings through Efficiency Improvements . . . . . . 1-4

1.3 Organization of the Report . . . . . . . . . . . . . . . . . 1-4

2.0 POTENTIAL ENERGY SAVINGS THROUGH MOTOR IMPROVEMENTS . . . 2-1

2.1 Motor Stocks in Developing Countries . . . . . . . . . . . . 2-1

2.2 Motor Efficiency . . . . . . . . . . . . . . . . . 2-2

2.3 Production of New Motors . . . . . . . . . . . . . . . 2-4

2.3.1 Imported Motors . . . . . . . . . . . . . . . 2-6

2.3.2 Local Capacity for Manufacturing High-Efficiency Motors . . . . 2-6

2.4 Economics of High-Efficiency Motors . . . . . . . . . . . . . . . 2-7

2.4.1 Results from Country Studies . . . . . . . . . . . . . . 2-7

2.5 Potential Sector-Wide Energy Savings through High-Efficiency Motors . . 2-9

2.6 Potential Energy Savings Through Multi-Speed Motors . . . . . . . . 2-10

2.7 Rewinding Practices and Improvement Possibilities . . . . . . . . . 2-11

2.7.1 Comparing Rewinds with New High-Efficiency Motors . . . . . 2-13

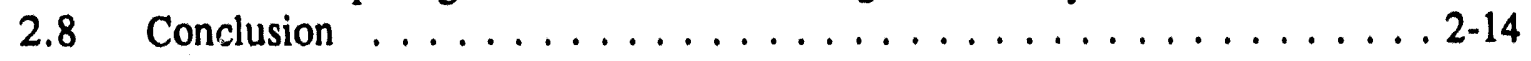

3.0 POTENTIAL ENERGY SAVINGS THROUGH OTHER SYSTEM

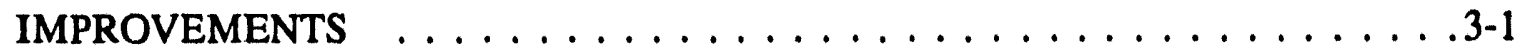

3.1 Reducing Oversizing in System Design . . . . . . . . . . . 3-1

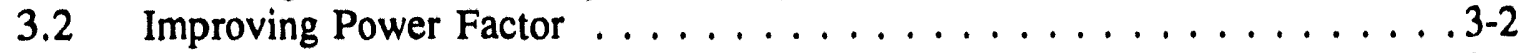

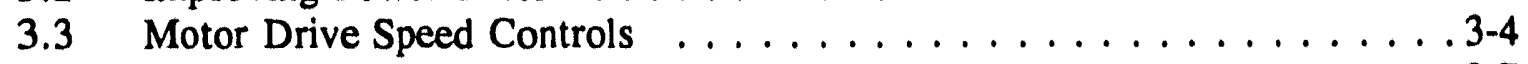

3.4 Improved Operation and Maintenance $\ldots \ldots \ldots \ldots \ldots \ldots \ldots . . \ldots 3$

3.5 Improved Mechanical Power Transmission . . . . . . . . . . . 3-8

3.6 Efficiency of Driven Equipment . . . . . . . . . . . . . 3-9

3.7 Summary of Savings from Other System Improvements $\ldots \ldots \ldots \ldots$. . . . . . . .

4.0 POLICIES TO PROMOTE ENERGY EFFICIENT MOTOR SYSTEMS . . . . . . 4-1

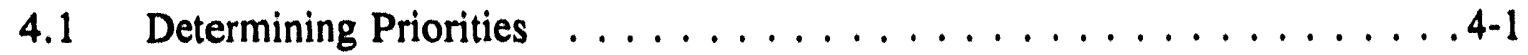

4.2 Barriers to Efficiency Improvement . . . . . . . . . . . . . 4-2

4.3 General Policies Affecting Industrial Investment Decisions . . . . . . . 4-4

4.3.1 Energy Pricing . . . . . . . . . . . . . . . . . 4-4

4.3.2 Trade and Investment Policy $\ldots \ldots \ldots \ldots \ldots \ldots \ldots \ldots . . \ldots$ 4-4

4.4 Education Programs . . . . . . . . . . . . . . . . . 4-5

4.5 Motor Efficiency Information $\ldots \ldots \ldots \ldots \ldots \ldots \ldots \ldots \ldots . \ldots .6 . \ldots . \ldots$

4.6 Motor Efficiency Standards . . . . . . . . . . . . . . . . 4-7

4.7 Technical Assistance Programs . . . . . . . . . . . . . . . . 4-8

4.8 Incentive Programs $\ldots \ldots \ldots \ldots \ldots \ldots \ldots \ldots \ldots \ldots . \ldots \ldots$ 
4.8.1 Rebate Programs . . . . . . . . . . . . . . . . . . 4-9

4.8.2 "Package" Incentive Programs . . . . . . . . . . . . . . 4-11

4.8.3 Loans and Grants . . . . . . . . . . . . . . . . . . 4-11

4.8.4 Tax Incentives . . . . . . . . . . . . . . . . . . . . 4-12

4.9 Research, Development and Demonstration (RD\&D) Programs . . . . 4 4-12

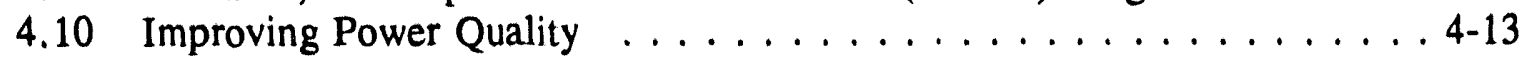

4.11 Issues and Priorities for Developing Countries . . . . . . . . . 4-13

APPENDIX: ECONOMICS OF ELECTRICITY CONSERVATION

INVESTMENTS $\ldots \ldots \ldots \ldots \ldots \ldots \ldots \ldots \ldots \ldots \ldots \ldots$ A-1

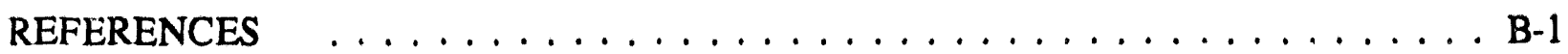

Note: We primarily present motor size in terms of horsepower (hp). $1 \mathrm{hp}-0.746$ kilowatts. 


\section{EXECUTIVE SUMMARY}

Developing countries are increasingly relying upon motor systems to power the expansion of their industrial sectors. Motor systems consume some $65-80 \%$ of industrial electricity in the large developing countries and perhaps an even greater share in the smaller countries. These motor systems are often less efficient than their counterparts in industrialized countries. Drawing on studies from Thailand, India, Brazil, China, Pakistan, and Costa Rica, we show that significant electricity savings are possible in new and existing motor systems. Many of the efficiency improvement opportunities we identify are cost-effective from a societal perspective, with the cost of conserved energy far below the long-run marginal cost of electricity.

The efficiency of a motor system is comprised of more than the efficiencies of the individual parts; design and operating characteristics affecting the interaction between components enter fundamentally in the calculus. As Figure E.1 illustrates, there are numerous junctures in the motor system where improvements can be made. There are two categories of basic improvements: General (and often synergistic) improvements that enhance the overall efficiency of the system, and high-efficiency technologies that target individual components. General improvements include operation and maintenance procedures, component sizing practices, and power quality both in the plant and in the supply system. While the potential for cost-effective electricity savings in developing countries appears to be large, a great deal of uncertainty is attached to the estimates, and not much empirical analysis has been carried out.

There has been much more analysis of the potential impact of higher-efficiency components in the motor system. For the six countries reviewed, the technical potential for electricity savings from high-efficiency motors is estimated at $1.5 \%$ to $4.7 \%$ of total industrial electricity use. Replacing a failed standard motor with a high-efficiency motor is cost-effective in all study countries (Table E.1). Other components for improving system efficiency include motor speed drive controls, multi-speed motors, properly rewound motors, fans, pumps, compressors, and transmission equipment. As an individual strategy, variable-speed drives appear to offer the greatest potential for electricity savings. The main deterrents to the penetration of highefficiency technologies are high initial cost (partly due to import duties) and limited availability. 


\begin{tabular}{|r|c|c|c|c||}
\hline \multicolumn{5}{|c|}{ Table E.1 Economics of for Replacing Standard with } \\
Energ-Efficient Motors*
\end{tabular}

- Short-run marginal cost

' Long-run marginal cost

- Energy-efficient motor

¿High vollage customer

- Low voltage customer

* See Table 2.4 on page 2.8 for specific assumptions underlying these values.

As an example, the cost-effective technical potential for reducing electricity consumption in India by improving motor system efficiency is estimated at $7 \%$ of projected national electricity use in 2005 (Figure E.2). Variable-speed drives offer the greatest potential savings, followed by general improvements relating to operation and maintenance, phase balancing, rewinding, and sizing.

Although many efficiency measures are attractive according to cost-effectiveness criteria from a societal perspective, barriers such as information gaps, a scarcity of skilled personnel, capital shortages, lack of local production of high-efficiency components and high import duties dissuade consumers from implementing them. Energy efficiency has historically ranked low on the list of characteristics plant managers look for when purchasing a motor, with least initial cost and short payback times instead the priority conditions. Given the difficult constraints facing industries in developing countries, an end-user's decision not to invest in energy-efficient motor systems is often a reasonable choice. Policies to reduce the dissonance between societal and consumer perspectives on cost-effectiveness include educating end-users on the multiple benefits of efficiency improvements, offering energy audits and other forms of technical assistance, providing incentives through rebates to purchasers and dealers, lowering import duties on highefficiency equipment, and improving the quality of the electricity supply system. Insights gleaned from the North American experience on overcoming barriers can help developing countries "leapfrog" over the pitfalls of trial and error approaches, but such strategies must be tailored to the unique circumstances of each country.

Some developing countries, particularly smaller ones, lack domestic production capability of energy-efficient products, and all countries lick significant market demand for such products. The lowering of import duties for components necessary to manufacture high-efficiency 
equipment can reduce costs, but the provision of financing and other incentives is critical to industrial consumers for whom minimizing first costs is a primary consideration. Experience in North America indicates that rebates or other incentives that cover a high percentage of the incremental cost of high-efficiency equipment may be required to stimulate demand.

Market transformation can be stimulated by the dynamic participation of utility companies. Substantive interaction between utilities and end-users will be necessary to determine how customers can best be served through energy-efficient technologies and practices. The experience of North American utilities regarding motor efficiency programs highlights the need to consult end-users regarding motor system preferences and to obtain distributors' support and participation in the programs.

Energy-efficient motor systems carry multiple benefits that are of particular significance as developing nations search for strategies to increase productivity and improve their competitiveness. Policy initiatives must be both vigorous to overcome the barriers to efficiency improvements and flexible to accommodate individual or country-specific circumstances. There are a number of fledgling motor efficiency programs in developing countries. For example, Brazil's national conservation program, PROCEL, is sponsoring a program to identify no- and low-cost electricity conservation measures for motor systems and other end uses. A utility program is planned in Thailand that will pay most of the incremental cost of high-efficiency new motors to the end-user. The best approach would be to develop a comprehensive package of policies and programs designed to address all aspects of motor system performance. Such an effort would require the participation of numerous entities, including utilities, government agencies, lending institutions, trade associations, manufacturers, vendors, ?.ıd end-users. Emerging utility programs should work closely with existing energy conservation organizations that have developed close contacts with industry. Utilities can also work with industry associations and Ministries of Industry to encourage domestic production of high-efficiency technologies. Lastly, governments can use existing industrial development channels to promote loans for manufacturers to upgrade or build new production. 


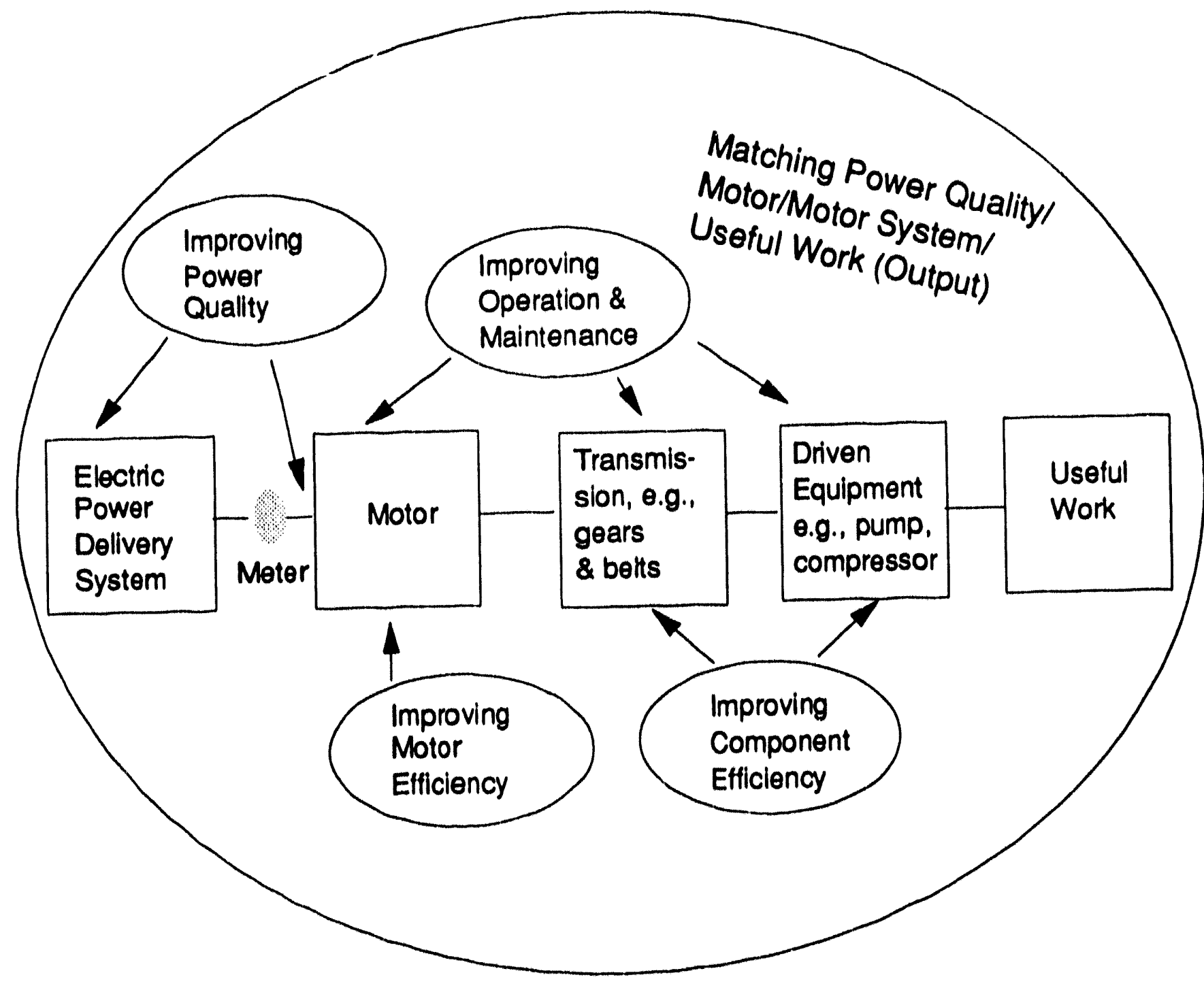

Figure E.1 Mechanisms for Improving Motor System Efficiency 


\section{Economic Potential for Electricity Savings From Motor System Improvements in India}

(\% of Projected 2005 All-Indla Electricity Use)

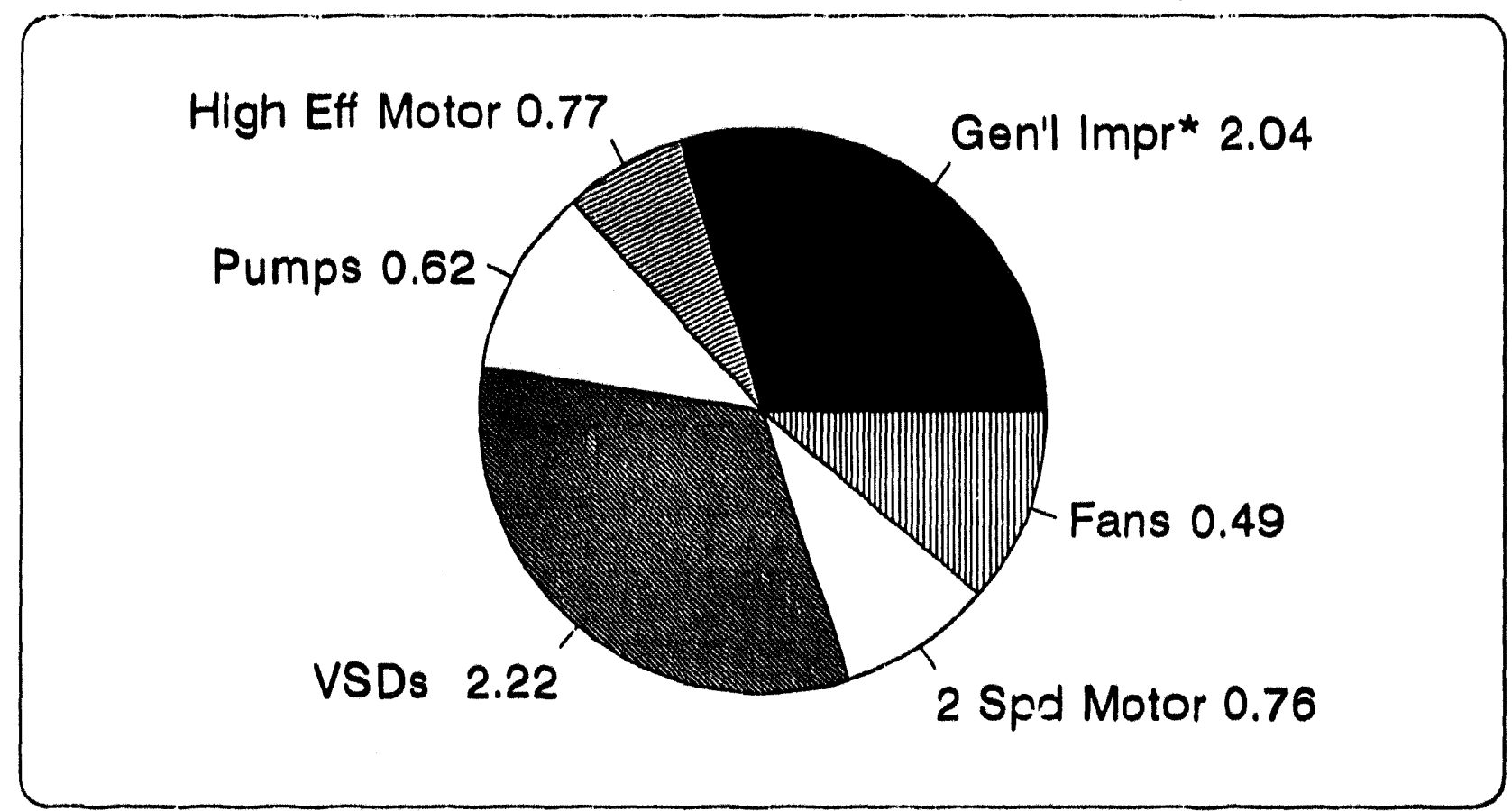

- General improvements include: Improved O\&M; phaso balancing; and rewinding and sizing practices. Source: Nadel, Kotharl, and Gopinath (1991)

Figure E.2 


\title{
1.0 INTRODUCTION
}

Motor systems are responsible for powering a wide range of industrial operations. In the drive to industrialize and improve productivity in developing countries, motor systems have played an increasingly important role. Recent estimates indicate that motor systems consume $65-80 \%$ of industrial electricity in large and mediun-size LDCs (Table 1.1).

Motor systems in developing countries are often comprised of outmoded components that are inefficiently designed and operated. They typically expend much more energy per unit of output than systems in industrialized countries. As we show in this report, significant efficiency improvements are possible in electric motors and the systems that they drive, often at a cost below that of new electricity supply. The use of efficient equipment in well-designed systems can significantly impact overall energy use. In most developing countries, the majority of electricity use in 2005 will be used to power equipment purchased between now and then.

\begin{tabular}{|c|c|c|c|c|c||}
\hline \multicolumn{2}{|c|}{ Table 1.1 Share of Industrial Electricily Consumed hy Motor Systems } \\
\hline & Brazil & China & India & Thailand & Pakistan \\
\hline \% of ind. elec. to motors & $49 \% *$ & $65 \%$ & $74 \%$ & $80 \%$ & $80 \%$ \\
\hline
\end{tabular}

\begin{abstract}
- The motor share of industrial electricity use in Brazil is low because surplus electricity from hydroelectric facilities in the 1981-86 period led the government to encourage the substitution of electricity for oil in thermal applicutions. In 1987, the special tariffs were discontinued as surplus supplies dwindled, and the share of electricity to motors is rising as a result.
\end{abstract}

Sources: See footnote 1.

Policies that encourage improvements in motor system efficiency can yield benefits to a number of different actors. For utilities, improvements in motor system efficiency can slow growth in electricity demand and help to ease the shortages that plague many countries. For industries, lower costs and enhanced productivity can result. For motor system equipment manufacturers, policies promoting conservation can help build a domestic market for more sophisticated products that can also be exported. At a national and international level, gains in electricity enduse efficiency will yield environmental benefits, reduce the need for electricity generation, and contribute to more productive use of scarce capital.

This report presents information on motor systems in developing countries and the potential to improve their efficiency. It draws primarily on studies of six countries: Thailand, India, Brazil, 
China, Pakistan and Costa Rica.' Two of the authors of this report (Greenberg and Nadel) participated in the studies of Thailand and India. They also were among the authors of a book on motor system efficiency, ${ }^{2}$ from which the present report also draws.

\subsection{Conceptual Overview of Motor System Efficiency}

The characteristics and configuration of the various components of a motor system determine its effectiveness. Ideally, a motor system is configured according to the work that needs to be accomplished and to the quality of the power supply. Energy losses can occur at many different points in the system, and will vary according to wire sizing, throttle or bypass valves, transmission type (shaft couplings, gears, belt drives, chains), driven equipment (pumps, fans, compressors), piping or ductwork, and the motor itself (Figure 1.1 shows losses from a hypothetical system).

There are basically three types of losses in motor systems: Electrical, magnetic, and mechanical losses. Each of these losses can be reduced by relatively simple procedures, though each procedure may involve somewhat higher production costs. ${ }^{3}$

'Unless otherwise noted, the sources for country-specific data prcsented in this report are as follows:

Brazil: H. Geller. 1991. Efficient Electricity Use: A Development Strategy for Brazil. Washington, D.C.: American Council for an Energy-Efficient Economy.

China: J. Sathaye. 1992. "Economics of Improving Efficiency of China's Electricity Supply and Use: Are Efficiency Investments Cost-effective?" Paper presented at the World Bank/Chinese Ministry of Energy Workshop on Coal Utilization and Energy Efficiency in China. April 22-25, 1992, Beijing. Revised May 25, 1992.

Costa Rica: RCG/Hagler, Bailly, Inc. and Oak Ridge National Laboratory. 1991. "Costa Rica: Power Sector Efficiency Assessment." Report prepared for the Office of Energy, U.S. AID.

India: S. Nadel, V. Kothari, and S. Gopinath. 1991. "Opportunities for Improving End-Use Electricity Efficiency in India." Report prepared for the World Bank. Washington, D.C.: American Council for an Energy-Efficient Economy.

Pakistan: P. Miller, H. Geller and A.T. de Almeida, 1992. "An Example of Energy Savings in LDCs: Improving Electrical Equipment in Pakistan. " Energy 17(10): 969-982.

Thailand: T. Fry, S. Greenberg, L. Peterson, and P. Rumsey. 1992. "Annex A: Industrial Sector Programs." In "Thailand: Promotion of Electricity Energy Efficiency." International Institute for Energy Conservation. Report prepared for the World Bank and the Global Environment Facility. Bangkok, Thailand: IIEC.

2S. Nadel, M. Shepard, S. Greenberg, G. Katz, and A.T. de Almeida. 1991. Eneray-Efficient Motor Systems. Washington, D.C.: American Council for an Energy-Efficient Economy.

'This discussion is adapted from Nadel et al., 1991. 
Electrical losses occur whenever current flows through a conductor and can thus occur at many points in the motor system. They are a function of the square of the current times the resistance ( $I^{2} R$ losses) and increase rapidly with motor load. Manufacturers and industrial firms can reduce $I^{2} R$ losses by using lower-resistance materials, such as larger diameter copper windings and larger diameter wires for in-plant electrical distribution.

Magnetic losses occur in the motor itself, due to eddy current and hysteresis. Manufacturers can reduce these losses by using larger cross-sections of iron in the stator and rotor, as well as thinner laminations and improved magnetic materials.

Mechanical losses appear as friction in the bearings, transmissions, and driven equipment and losses in cooling fans. Manufacturers can decrease mechanical losses by using higher quality bearing assemblies, high efficiency driven equipment, and improved fan designs.

Stray losses, specific to the motor itself, take many forms including leakage flux, non-uniform current distribution, imperfect air gaps, and irregularities in the air gap flux density. They can be reduced by optimizing motor design and improving manufacturing tolerances.

The key to increasing motor system efficiency is to utilize high performance technologies in a well-designed system, with ongoing attention to proper operation and maintenance techniques. Replacing a failed standard-efficiency motor with a high-efficiency motor is an obvious and effective conservation technique, but it represents only part of the potential for improvement. Avoiding oversizing in system desizn is also important, since the efficiency of motors and driven equipment drops off sharply below about $40 \%$ of rated load. Controlling the motor's speed in appropriate applications with electronic variable-speed drive rather than traditional controls can yield sizable energy savings, and also extend equipment life by allowing for gentle start up and shut-down. Proper selection, installation, and maintenance of transmission hardware (belts, gears, chains) can greatly enhance system performance and efficiency. Improving the quality of the electricity that powers the motor can reduce energy use, enhance equipment performance and process control, and reduce downtime from damaged equipment. ${ }^{4}$ Using correctly-sized wires and improved transformers in the power lines supplying the motor can reduce distribution losses. Lastly, carefui, ongoing monitoring and maintenance of the entire motor system can save considerable energy, and contribute to more reliable operation and extended equipment life.

We stress, however, that the motor system is but one element, albeit an important one, in the production process. This report does not examine options for fundamental changes in process desigi. Process changes thai reduce loads can significantly reduce electricity requirements. Process alternatives require in-depth study of particular applications.

\footnotetext{
"At the plant level, this may involve monitoring and repair of faulty devices or use of specialized powerconditioning equipment; actions by electricity supply companies can also improve power quality - this is especially important in many developing countries.
} 


\subsection{Estimating Electricity Savings through Efficiency Improvements}

The potential efficiency gains and associated electricity savings through the penetration of highefficiency technologies can be evaluated several ways. The technical potential is an estimate of the reduction in electricity use that could be achieved if a commercially available technology were adopted across the entire applicable stock. It thus represents the outer bound of electricity savings possible. The technical potential can be evaluated through either a static or dynamic approach. A static approach examines efficiency gains relative to the current stock, whereby standard equipment is instantaneously replaced. This method is easy to calculate, but does not account for the market dynamics of the real world. A more realistic approach would consider the evolution of the equipment stock and the rate of turnover.

The economic potential evaluates electricity savings through widespread adoption of measures considered cost-effective, usually from a societal perspective. One measure of cost-effectiveness from a societal viewpoint is the cost of conserved energy (CCE), the levelized average cost of a measure per $\mathrm{kWh}$ saved. If the CCE is below the long-run marginal cost (LRMC) of providing electricity, the measure is considered cost-effective. Consumers use very different criteria to assess a conservation measure, often relying on the simple payback. The appendix provides firther discussion of cost-effectiveness criteria.

The dissonance between consumer and societal perspectives and other barriers to efficiency improvements often deter adoption of some technologies, and even with strong policies and programs the achievable savings will be lower than the economic potential. Estimating the achievable savings requires assumptions regarding the dynamics of market processes and the impact of policies and programs on consumer decisions. Estimates must often fill the gaps from lack of data on end-use patterns, production capability, current and future stock characteristics, and other variables. There is little examination in the studies cited in this report of achievable savings; the technical and economic potentials are the main focus.

\subsection{Organization of the Report}

Several important points stand out in this report: (1) there is large potential for influencing motor system efficiency; (2) improving the intrinsic efficiency of the equipment itself represents only part of the potential; (3) the design and installation of a system plays a key role; (4) how the user manages the operation of the entire system is very important; and (5) measures that improve energy efficiency often provide other benefits as well.

These concepts are developed further as we explore the technical potential for motor efficiency improvements and examine policy mechanisms for their promotion. Section 2 analyzes potential efficiency improvements to the motor itself. Potential efficiency improvements to the general system are more difficult to quantify, but as indicated in Section 3, even modest improvements in operation, maintenance, and design can provide significant energy savings. Section 4 moves from technical potentials to the realm of policy-making, offering insight into the promotion of energy efficient development through economic, regulatory, and educational incentives. 


\section{Energy Losses \\ for a Hypothetical Motor System}

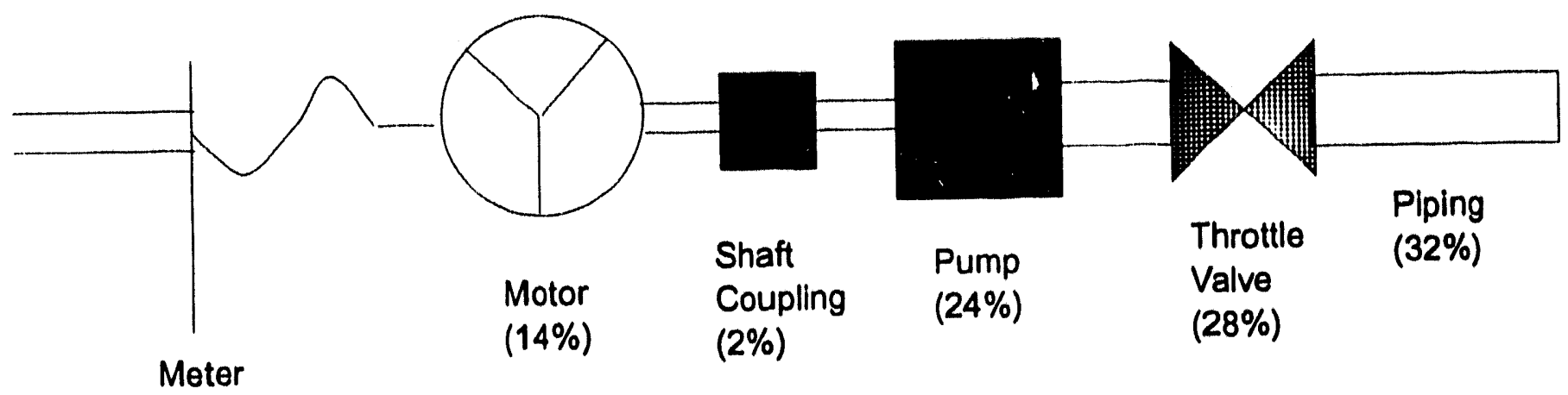

Figure 1.1

Source: Baldwin, 1989, in Johansson et al., 1989 


\subsection{POTENTIAL ENERGY SAVINGS THROUGH MOTOR IMPROVEMENTS}

In this section we discuss the potential for improving the efficiency of motors, as distinct from improving the efficiency of the motor system as a whole. The amount of information on the motor itself - the current stock, production characteristics, and efficiency improvement potential - calls for its selective treatment. Nevertheless, we emphasize a systems approach to efficiency improvement that examines both the components of the system and the linkages between them. We discuss the efficiency savings potential from other system components in Section 3.

Over $90 \%$ of the input energy into a well-designed 10 -hp motor can be converted to shaft power. In developing countries, much lower efficiencies are common, and relatively simple improvements in motor design and maintenance can save energy and money. The current operating efficiencies of motor stocks in developing countries are shaped by the interplay of economic, technological, and political variables that to varying extents can be controlled. Imports, comprised both of new motors and used, often lower efficiency motors, play an important role in shaping stock characteristics in some countries. Other variables affecting the motor stock include subsidized electricity rates, power fluctuations and outages, macroeconomic variables like inflation and lack of hard currency, and lack of domestic motor production capability.

\subsection{Motor Stocks in Developing Countries}

Though the motor stock varies among developing countries, there are some common characteristics. The vintage of motor stocks is often old. The low cost of labor and the high initial cost of new motors encourages motor rewinding over motor replacement. Access to highefficiency motors is limited, and prices often inhibit their purchase. The sophistication of domestic manufacture of motor systems depends on the size and shape of the industrial sector; countries with large sectors like India tend to produce a wider range of motors than smaller countries whose industrial sector is less-developed. While large manufacturers often have the capability to produce motors comparable in efficiency to the best motors on the world market, motors produced by small manufacturers tend to have low efficiencies.

The distribution of motor electricity use by motor size varies among countries. In India and Thailand, it is estimated that motors over 50 horsepower (hp) consume approximately $70 \%$ of the electricity used to power motors (Figure 2.1). In Thailand, projected data for 1993 indicate that motors greater than 500 -hp comprise only $0.4 \%$ of the stock, but use nearly $50 \%$ of motor electricity (Table 2.1). 


\begin{tabular}{|c|c|c|}
\hline Slze Range (hp) & Motors in Use $(000)$ & Energy Share \\
\hline $0-4$ & 566.9 & $4.4 \%$ \\
\hline $5-19$ & 188.0 & $8.0 \%$ \\
\hline $20-49$ & 60.9 & $18.1 \%$ \\
\hline $50-124$ & 15.0 & $10.4 \%$ \\
\hline $125-499$ & 4.3 & $10.3 \%$ \\
\hline $500+$ & 3.6 & $48.7 \%$ \\
\hline Total & 838.7 & $100.0 \%$ \\
\hline
\end{tabular}

In Brazil, the data indicate that 1- to 40-hp motors consume over $60 \%$ of motor electricity. The reason for the disparity between Brazil and India and Thailand is not clear.

\subsection{Motor Emstency}

Motor efficiency is the ratio of mechanical output to electrical input. The rated efficiency is the efficiency of a new motor, while the operating efficiency is often lower as time and inadequate operation and maintenance lead to performance degradation. Different efficiency tests can produce different results (Table 2.2). Many countries (especially the snialler ones) do not have standardized efficiency testing procedures, and the motor manufacturers thus have considerable latitude in rating motor efficiency. This is particularly problematic with the small manufacturers that only market their products locally. Some countries do not currently have the capability to test motor efficiency domestically. Further, there is no internationally accepted definition of "high-" and "standard-" efficiency. Sathaye (1992) found that motors considered "highefficiency" in China actually have about the same efficiency as standard motors in the U.S.

The accuracy of test methods varies by the specification and the assumptions that lay behind them. For example, the European International Electrotechnical Commission (IEC) Standard 342 , the most common method used around the world except in North America and Japan, assumes all stray losses are fixed at $0.5 \%$ of full load power, while the Japanese Electrotechnical Commission (JEC) standard ignores stray losses altogether (Nadel et al., 1991). The JEC standard is misleading given that stray losses commonly represent $10-15 \%$ of the motor losses at full load; stray losses will then account for 1.5-2.25\% of the full load power for a motor with an efficiency of $85 \%$. The Canadian Standards Association (CSA) standard and the National Electrical Manufacturers' Association (NEMA) standards evaluate stray losses and offer tighter specifications to minimize subjectivity and operator errors. Both methods are based on the 
Institute of Electrical and Electronics Engineers (IEEE) Test Method 112B, which indirectly measures stray losses.

\begin{tabular}{|c|c|c|}
\hline \multicolumn{3}{|c|}{$\begin{array}{l}\text { Table } 2.2 \text { Motor Efriciencies } \\
\text { According to Different Teating Methods }\end{array}$} \\
\hline & \multicolumn{2}{|c|}{ Full load efficiency (\%) } \\
\hline Test & 7.5-hp & 20-hp \\
\hline $\operatorname{CSA} C 390$ & 80.3 & 86.9 \\
\hline NEMA MO-1 & 80.3 & 86.9 \\
\hline IEC-34-2 & 82.3 & 89.4 \\
\hline JEC-37 & 85.0 & 90.4 \\
\hline
\end{tabular}

CSA: Canadian Standards Association

NEMA: $\quad$ National Electrical Manufucturers' Associution

IEC: International Electrotechnical Commission in Europe

JEC: Japanese Electrotechnical Commission

Source: BC Hydro, 1988, in Nadel et al., 1991

For a given motor design, larger motors tend to be more efficient than smaller motors and the average efficiency of motor stocks can be influenced by changing market shares for differentsized motors. A trend towards larger motors is reflected in new sales data for both India and Thailand. Combining industrial forecast data for Thailand with survey data on motor size, usage, and efficiency estimates indicates that motors over 125 -hp will prove pivotal in the future economy. In Brazil, estimates are that three-phase induction motors in the 1-hp to 10-hp range consume the bulk of motor electricity, but new production in terms of electricity consumed is dominated by motors over 200-hp.

Operating efficiencies in the field are likely to be lower than the rated efficiencies due to oversizing of motors, power quality problems, poor rewinding of motors, less than adequate motor maintenance and other operational factors. In India, a field survey conducted by the Tata Energy Research Institute found that the efficiency of motors in the field (calculated for full load) ranged from 4-13\% lower than the values reported by manufacturers in their catalogs (Anand and Kothari, 1990). The discrepancy was highest for small motors and lowest for large motors. For a typical mid-size motor $(20-\mathrm{hp})$, the motor in the field consumed $7 \%$ more power than its indicated rating. 
Large countries like India and Brazil have the capability to produce all sizes of motors; small countries such as Thailand or Pakistan rely more upon imports, particularly for the larger motors. In all of the study countries, small motors tend to be less efficient than their counterparts in the industrialized world. These motors are often produced by small local manufacturers and marketed regionally; using poor quality materials like mild steel and impure copper, these manufacturers produce motors with low initial costs to satisfy consumer demands. In Pakistan, about $25 \%$ of the total hp introduced domestically each year is from small manufactur: :s, whose motors are priced $50 \%$ to $60 \%$ lower than those of the major manufacturers.

Where large motors (above $200 \mathrm{hp}$ ) ure produced, they are usually made either by multinational companies such as General Electric, Siemens, and Asea Brown Boveri, or by local companies using designs licensed from a multinational company. These motors are produced using high-quality materials, and their efficiency is on a par with that of motors produced in industrialized countries.

Ordinary induction motors in the size range of $1.200 \mathrm{hp}$ are usually produced by national companies, and are often less efficient than comparable motors produced in industrialized countries. Table 2.3 presents data on the reported test efficiency of motors of up to $200 \mathrm{hp}$ produced in India, Thailand, and Brazil, with U.S. data presented for comparison. Only the Indian data are directly comparable with the U.S. data, since the same testing procedures are used in both cases (based on IEEE Standard 112-Method B). ${ }^{1}$ Manufacturers in Thailand and Brazil use either the European or Japanese test procedures, both of which yield higher efficiencies than the IEEE procedure.

Except for very small ( $1.2 \mathrm{hp}$ ) motors, the Indian standard-efficiency motors appear to be roughly comparable to U.S. standard motors. ${ }^{2}$ Indian high-efficiency motors are slightly less efficient $(\sim 0.5 \%)$ than comparable U.S. motors due to the use of better-quality steel in the U.S. motors. The data in Table 2.3 refer only to companies in the organized sector; some of the small-scale manufacturers who make only small motors produce motors with lower efficiencies than the manufacturers in the organized sector.

\footnotetext{
'The Indian efficiency numbers in Table 2.3 are taken from manufaclurers' catalogs (Anand, 1993). Catalog information is most likely to be based on design rather than test values, which are generally available to customers only upon request. The difference, however, would not be very large.

The standards in India allowed for a +1 . tolerance on reported values of efficiency. This applied to standard motors (and still applies). Manufucturers generally report values to their advantage. This has changed in the new standards which apply to energy-efficient motors: manufucturers have to report the minimum guaranteed value.
} 

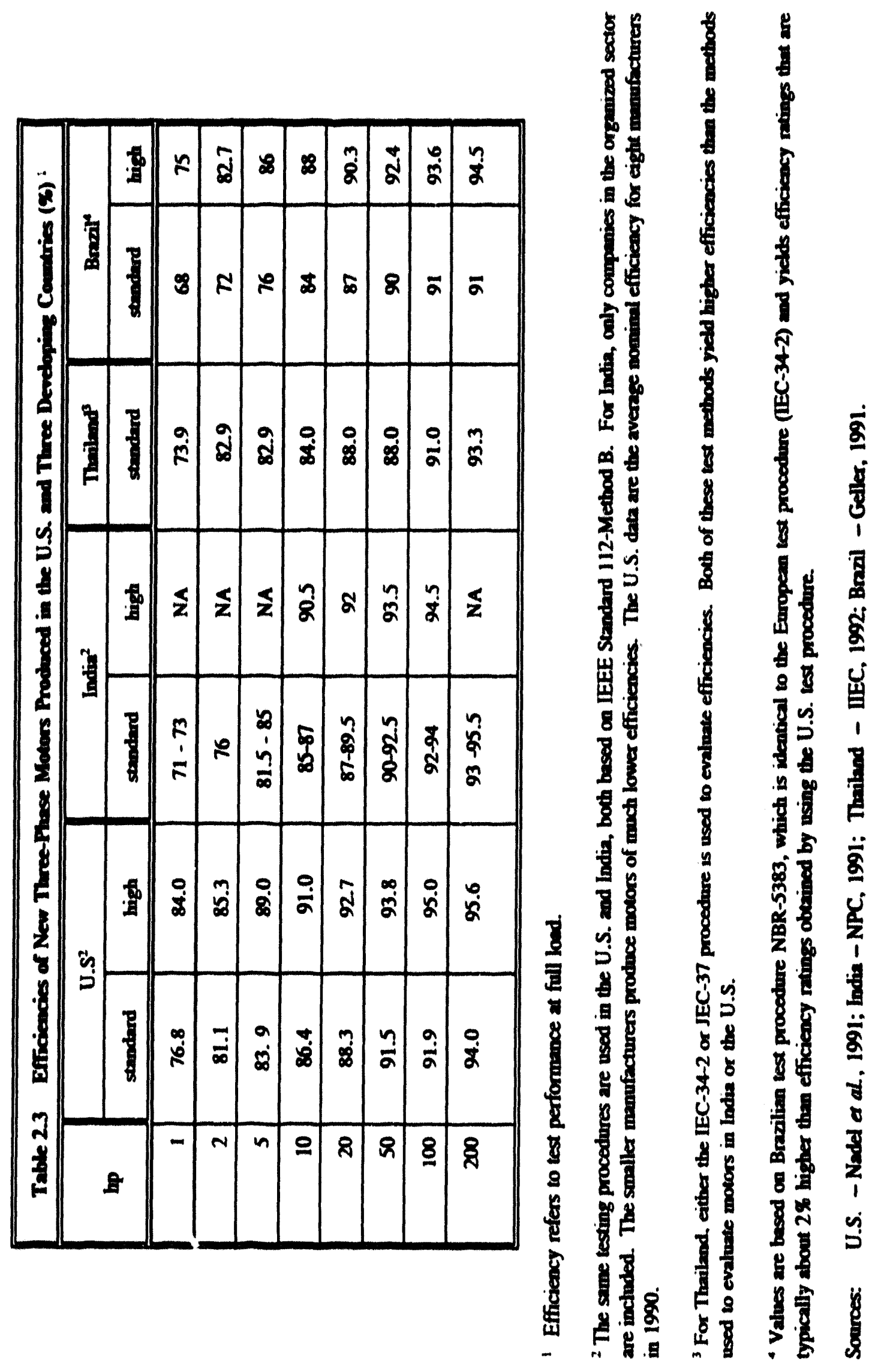
Direct comparison of the Thai and Brazilian motors with the U.S. and Indian motors is difficult since the test procedures are different. Since the reported efficiencies are lower than the U.S. values for most motor sizes, and the Brazilian and Thai test procedures yield higher efficiencies than the U.S. procedure, it is safe to conclude that the motors produced in those two countries are of markedly lower efficiency than U.S. motors of comparable size. The "high-efficiency" motors produced in Brazil are of much lower efficiency than high-efficiency U.S. motors.

\subsubsection{Imported Motors}

Since there is little domestic demand for large or high-efficiency motors in most developing countries and domestic production of such motors is limited, imports supply the bulk of these devices. In Brazil, all motors above 200-hp are imported; in Thailand, imports account for all motors above 125-hp. Efficiencies of new motors imported from OECD countries are generally comparable to motors sold in OECD countries. The efficiencies of motors imported from the Former Eastern Bloc or other developing countries may be lower, but there is little data on either efficiencies or numbers of imports from these countries. Particularly for smaller countries, imports may comprise a large fraction of the motor market. Pakistan imports over 25\% of its total annual hp from China (on the order of 8000 motors per year). Chinese motors are low cost but have similar characteristics in terms of power factor and efficiency to the motors made by the large domestic manufacturers in Pakistan.

The incremental costs of high-efficiency motors are greater in developing countries than in the industrialized countries, in part due to import duties. In Thailand, the less than 5\% of new motors reported to be high-efficiency units are all imported and subject to a 35\% import tax (both standard- and high-efficiency molors are subject to this tax). Some industrial users say that the added cost of the import tax is a primary obstacle to their buying higher efficiency motors.

\subsubsection{Local Capacity for Manufacturing High-Efficiency Motors}

The domestic production of high-efficiency motors depends on three key factors: Domestic demand, technical expertise of the manufacturers, and the availability of high-quality materials like silicon steel. The smaller, less developed countries may be limited by all three factors, while larger countries are more commonly limited by low demand. Manufacturers in Thailand, India, Brazil, and Pakistan report that low domestic demand is the primary limiting factor. In Brazil, the largest manufacturer of induction motors (WEG Motores Lida.) has developed a highefficiency motor for export that is not sold domestically. Indian manufacturers do produce highefficiency motors in a variety of sizes for domestic sale, but discussions with manufacturers indicate that they account for less than 1\% of motor sales in India today.

With increased demand for high-efficiency motors, domestic production, at least in the larger countries, may likewise expand. However, smaller or less industrially-developed countries may lack the near-term capability for producing high-efficiency motors. Further, there may be 
limited availability of materials required for the manufacture of high-efficiency equipment. In India, for example, imported high quality copper is required for the manufacture of highefficiency motors, but the government restricts allowable copper imports.

\subsection{Economics of High-Emclency Motors}

The economic benefit of a high-efficiency motor depends on its incremental cost relative to a standard motor, annual usage, electricity costs, lifetimes of the motors, and the discount rate used to evaluate future savings. Energy efficiency has historically ranked low on the list of characteristics that plant managers look for when purchasing a motor, with least initial cost instead the most important condition. List prices of high-efficiency motors in the U.S. are 20\% to $25 \%$ higher than the standard-efficiency models, but the mark-up on high-efficiency motors in developing countries is often greater than that. In Brazil, for example, there is a $30 \%$ to 60\% difference between the price of standard- and high-efficiency motors.

Figure 2.2 illustrates how the payback period for the replacement of a standard with a highefficiency motor in the U.S. varies according to the number of operating hours and the motor size. For motors up to 100-hp, the payback for new high-efficiency totally enclosed, fancooled (TEFC) inotors versus new standard TEFC motors is two years or less for operation of 4000 hours per year or more. Nole how payback rises sharply for motors above 150-hp, however. In the U.S., most industrial consumers will not invest in a measure unless the resulting energy savings will yield simple payback within two or three years; in developing countries, the required simple payback is likely even shorter.

Payback is an important consideration from the viewpoint of the industrial consumer, but is not a true measure of cost-effectiveness. Life-cycle cost analysis is more appropriate, especially when considering large investments and equipment that have long lifetimes. Using this approach, Figure 2.3 illustrates that for high-efficiency motors of 100-hp and below, the presentvalue savings are greater than the marginal cost even with very low operation (e.g., less than 250 hours per year). The break-even point for the largest model considered (250-hp) is about 1700 hours per year.

\subsubsection{Results from Country Studies}

Table 2.4 provides estimates of the cost of conserved energy (CCE) for replacing failed standard motors in the 8-50 hp size range with high-efficiency motors in India, Costa Rica, Brazil, and Pakistan. Though the assumptions used for estimating the CCE vary, high-efficiency motors are found to be very cost-effective for each case. In India and Brazil, where the analyses assumed annual operation of 4000 hours, the CCE is less than $\$ 0.02 / \mathrm{kWh}$. 


\begin{tabular}{|c|c|c|c|c|}
\hline \multirow[t]{2}{*}{ Tuble 2.4} & \multicolumn{4}{|c|}{$\begin{array}{l}\text { Cost of Conserved Energy Eatimates for Replacing Standard } \\
\text { with Hligh-Emclency Motors }\end{array}$} \\
\hline & India & Costa Rica & Brazil & Pukistan \\
\hline $\mathrm{CCE}$ & 1 akWh & $2.6 \mathrm{kPWh}$ & $1.4 \mathrm{kWh}$ & - \\
\hline $\begin{array}{l}\text { Electriclty } \operatorname{Cost} \\
\text { SRMC }\end{array}$ & $\begin{array}{l}3.6105 .2 \\
1 / \mathrm{kWh}\end{array}$ & - & $\begin{array}{l}3.7^{\circ} 108.3^{4} \\
e / k W h\end{array}$ & $3.8 \mathrm{kWh}$ \\
\hline $\begin{array}{l}\text { Eloctricily Coul } \\
\text { LRMC }\end{array}$ & $\begin{array}{l}7.1 \text { to } 8.1 \\
1 / \mathrm{kWh}\end{array}$ & $6.5 \mathrm{~d} / \mathrm{kWh}$ & - & $\begin{array}{l}6.6107 .2 \\
\text { lkWh }\end{array}$ \\
\hline Simple Payback & - & $1.2 \mathrm{yr}$ & $1.3^{4} \cdot 2.9^{\circ} \mathrm{yr}$ & $0.5 \ln 1.8 y$ \\
\hline \multicolumn{5}{|c|}{ Assumptions } \\
\hline Molor Size & 20-hp & 7.8.hp & 10.hp & so-hp \\
\hline $\begin{array}{r}\text { Annual } \\
\text { Operation }\end{array}$ & $4,200 \mathrm{hr}$ & $2,600 \mathrm{hr}$ & $4,000 \mathrm{hr}$ & $4,000 \mathrm{hr}$ \\
\hline Lifeume & $30 \mathrm{yr}$ & $9.3 \mathrm{yr}$ & $15 \mathrm{yr}$ & $10 \mathrm{yr}$ \\
\hline $\begin{array}{l}\text { Incremental } \\
\text { Cost of HEM }\end{array}$ & $\begin{array}{l}+30 \% \\
(\$ 220)\end{array}$ & $+\$ 118$ & $+\$ 174$ & $+30 \%$ \\
\hline $\begin{array}{r}\text { Roal Discount } \\
\text { Rate }\end{array}$ & $10 \%$ & $12 \%$ & $10 \%$ & $8 \%$ \\
\hline $\begin{array}{l}\text { Incroase in } \\
\text { Efricioncy }\end{array}$ & $3.5 \%$ & $7.2 \%$ & $4.5 \%$ & $4.0 \%$ \\
\hline
\end{tabular}

Short-run marginal cost

Long-run marginal cost

High voluage customer

- Low voluge customer

- High.efficiency molor

In Thailand, high-efficiency motors were estimated to have a CCE less than the avoided cost of electricity in all but the smallest size range (Table 2.5). The CCE declines as motor size increases. 


\begin{tabular}{||l|c|c|c|}
\hline \multicolumn{2}{|c|}{ Table 2.5 } & Cost-ErTextiveneas of High-Emclency vo. Standard New Moton in Thalland \\
\hline Slae Range (hp) & $\begin{array}{c}\text { Incremental Cost } \\
\text { (S/avg motor) }\end{array}$ & $\begin{array}{c}\text { Savings } \\
\text { (kWh/avg motor) }\end{array}$ & $\begin{array}{c}\text { CCE } \\
\text { (C/kWh) }\end{array}$ \\
\hline $0-4$ & 51 & 120 & 5.6 \\
\hline $5-19$ & 172 & 499 & 4.6 \\
\hline $20-49$ & 469 & 1,702 & 3.6 \\
\hline $50-124$ & 828 & 5,280 & 2.1 \\
\hline $125-499$ & 2035 & 9,765 & 2.7 \\
\hline $500+$ & 7532 & 54,219 & 1.8 \\
\hline
\end{tabular}

- Asuumea a 10\% diecount rate, 15 year lifotime.

Cost of avoided generation $-4.9 \mathrm{c} / \mathrm{kWh}$ (assuming 14\% T\&D loss)

High-efficiency motors can also be cost-effective replacements for operating standard motors, particularly between 5-hp and 100-hp. A Stanford University study (Wilke and Ikuenobe, 1987) found that many motors operate below nominal efficiency ratings due to rewinding damage, oversizing, and other factors. The payback period associated with downsizing and replacing standard motors with high-efficiency motors was five years. Replacing operating motors is particularly economis, for large companies that can negotiate price breaks on equipment.

\subsection{Potential Sector-Wide Energy Savings through High-Efriclency Motors}

The technical potential for electricity savings available through widespread adoption of highefficiency motors is estimated at $1.5 \%$ to $5 \%$ of industrial sector electricity use for the study countries. The variance in the studies is due to alternative assumptions regarding the market penetration of high-efficiency motors, the efficiencies of the mot'sr being replaced and the highefficiency motor, and the growth of industrial electricity use. The technical potential represents the outer bound on electricity savings, with cost-effective savings somewhat below this level, and achievable savings lower still. Section 4 discusses why achievable savings differ from both technical and cost-effective savings and policy mechanisms to help reduce the difference (see Section 1.2 for definitions of technical, economic, and achievable savings).

In Thailand, if all motors in use could be converted to high-efficiency motors in 1993, an estimated 3.3\% of total industrial electricity could be saved." For Brazil, a similar analysis

The eatimated annual onergy savings per motor duo to high-efficiency motors is $8.7 \%$ for the $0.5 \mathrm{hp}$ rango, 7.7\% for $6.20 \mathrm{hp}, 6.2 \%$ for $21-50 \mathrm{hp}$, and $2.4 \%$ for all larger motors. 
finds the total savings potential to be about $3 \%$ of total industrial electricity use in $1988 .{ }^{4}$ In this case, the greatest savings are achieved through the replacement of motors in the range of $1.10 \mathrm{hp}$.

In Costa Rica, high-efficiency motors are estimated to have the potential to achieve a reduction of $4.7 \%$ of total industrial electricity use in 2005.'

The Pakistan study estimates the energy savings from the replacement of failed standard motors with new high-efficiency motors and the installation of high-efficiency units in new facilities. The savings in the year 2005 are estimated to be $1060 \mathrm{GWh}$ (3\% in industrial electricity consumption) and $220 \mathrm{MW}$ of base-load generating capacity. ${ }^{6}$

The India study assumes that high-efficiency motors are not stitable for all applications and are appropriate primarily when an existing motor wears out and needs replacement. The study finds that high-efficiency motors will be technically feasible and cost-effective for about $55 \%$ of motor applications by 2005 . Savings are estimated at $2 \%$ of motor electricity (or $1.5 \%$ of total industrial electricity), with an energy savings of 3,860 GWh (low case) to 6,077 GWh (high case). Estimated peak generation savings range from $1.1 \mathrm{GW}$ to $1.8 \mathrm{GW}$.

\subsection{Potentlal Energy Savings Through Multi-Speed Motors}

Multi-speed motors generally contain two (or more) sets of windings, which allow the motor to operate at different discrete speeds. Use of a multi-speed motor allows gross changes in motor speed to take place at the motor, with fine tuning left to traditional control devices such as guide vanes, dampers, or valves. Multi-speed motors provide a fairly low-cost approach to motor speed control. Variable-speed drives, as discussed later in Section 3.3, can also provide speed control.

Multi-speed motors are not appropriate for all motor applications. First, not all applications need variable speed. Second, multi-speed motors are typically larger than one-speed mutors,

\footnotetext{
This study lookn only at the savings potential from three-phase induction motors below 200 hp (approximately $80 \%$ of electricity use).

The study assumes partial market penetration of $73 \%$ (full implementation is assumed at $80 \%$ ) can occur by 2005. The study assumes the standard motor is 7.8-hp, though the average motor size in Costa Rica is over 20-hp. Since replacement of amaller motors with energy officient motors yields a greater percent savings than would a largor motor, the Costa Rica study may overstate the potential savings.

This assumes there is a $4 \%$ average efficiency improvement when using energy efficient motors, that motors keep their approximato $80 \%$ share of industrial electricity consumption, and that industrial electricity use continues to grow at the rate of $8.75 \%$ for the next two decades. In the high case, existing standard motors are replaced by more efficient models over 12 year period (1988-2000).
} 
so physical space limitations may apply.? Third, for some applications, variable speed drives used in conjunction with a single-speed motor are the cost-effective alternative.

In India, motors accounting for $25 \%$ of motor energy use are estimated to be replaceable with multi-speed motors. Two-speed (and even three-speed) motors are produced by se-eral manufacturers. These motors typically cost $30-80 \%$ more than a similar-sized single-speed motor. Energy savings vary depending on the application but savings of 8-10\% are estimated. For a typical application involving a 30 -hp motor, the incremental cost relative to a single-speed motor is approximately $\$ 283 / \mathrm{hp}$, and the CCE is $1.1 \mathrm{c} / \mathrm{kWh}^{8}$ (while the LRMC of electricity is 7.1 to $8.1 \mathrm{c} / \mathrm{kWh}$ ). Savings potential from two-speed motors in 2005 is estimated to be al out the same as for high-efficiency motors, or $2 \%$ of motor electricity.

\subsection{Rewinding Practices and Improvement Possibilities}

When a motor fails it is either replaced or rewound. Rewinding consists of stripping and replacing old windings with new wire. In terms of initial cost, rewinding is very economical; the rebuilt motor saves on raw materials costs by using the same rotor and stator iron and case. Rewinding a motor several times is not uncommon. While in theory rewinding can provide the same efficiency as a new motor, in practice performance degradation is common (Montgomery, 1989). Damage may occur during the rewinding process or may escape undetected from a preexisting condition. In some developing countries, such as Pakistan, the stator is typically heated in an oven to soften the windings for removal. If temperatures are allowed to exceed a certain threshold, core damage can result due mainly to damage to the insulation between the laminations in the core. Few motors are tested afterwards for core loss or overall efficiency.

Motor rewind practices can be improved with proper training and follow-up analysis. Simple measures for improving rewind practices in developing countries include:

Non-damaging windings removal. Windings can be removed manually after heating in moderate temperature ovens $\left(150^{\circ}-300^{\circ} \mathrm{C}\right)$, or by other techniques.

Pre-rewind testing. Motors should be checked for mechanical damage and core losses. If testing reveals permanent damage, the motor should be scrapped, unless repair is feasible.

Rewinding. Rewinds should use the same number or turns as the original motor

\footnotetext{
'In the U.S. and other industrialized countries, a special type of two-speed motor is produced called a poleamplitude-modulation (PAM) motor. PAM motors are approximateiy the same size as single-speed motors and cost about the same as conventional two-speed motors.

These calculations, which are relative to a $90 \%$-efficient single-speed motor, assume $9 \%$ savings and a 5815 incremental cost ( $55 \%$ more than a single-speed motor of the same size).
} 
windings. Copper wire of the same diameter or greater should be used. Insulation should be of appropriate class.

Post-rewind testing. Motors should be checked for core losses to ensure that no damage occurred during the repair process. Again, if testing reveals damage, the motor should be scrapped. Primitive testing for core loss can be conducted at virtually no cost. Electronic core-loss spot meters start at about $\$ 8,000$ for $10 \mathrm{kVA}$ models.

The market for motor rewinds in developing countries is large due to the low cost of labor and the high initial cost of a new motor. A motor may be rewound several times during its lifetime; a large motor may be rewound 5-6 times before it is replaced. The rewind rate is thus much higher than in industrialized countries, as Table 2.6 illustrates.

\begin{tabular}{||l|c|c|}
\hline \multicolumn{2}{|c|}{ Table 2.6 } & \multicolumn{2}{c|}{$\begin{array}{c}\text { Industrial Motor Rewinds for } \\
\text { in Thailand }\end{array}$} \\
\hline \hline Size Range (HP) & Rewind Rate* & 1993 Rewinds \\
\hline \hline $0-45$ & $20 \%$ & 113,400 \\
\hline $5-19$ & $20 \%$ & 37,600 \\
\hline $20-49$ & $15 \%$ & 9,150 \\
\hline $50-124$ & $15 \%$ & 2,250 \\
\hline $125-499$ & $10 \%$ & 400 \\
\hline $500+$ & $10 \%$ & 400 \\
\hline
\end{tabular}

Note: Estimates based on interviews with factory managers and rewind shops

* Rewind rate refers to the percent of installed motors that are rewound.

The energy savings from improved rewinding techniques are difficult to estimate. General Electric conducted a study in the U.S. on rewind losses that found an increase in core losses ranging from $0-400 \%$ (compared to the rating when new), with an average increase of $32 \%$. The study found losses to be most pronounced in the larger motors. At a typical load of $75 \%$, core losses represent about $1 / 4$ of total losses. Thus, for a motor at $90 \%$ efficiency with a load of $75 \%, 2.5 \%$ of input energy is attributed to core losses. A core loss increase of $40 \%$ would reduce that motor's efficiency by $1 \%$. Nadel et al. (1991) estimate that poor rewinds cause a $1 \%$ efficiency loss across the entire U.S. motor stock. In developing countries, rewinds 
potentially could cause even higher losses. ${ }^{9}$ In India, for example, motors are commonly heated in high-temperature open fires and core damage is the likely result. No estimates were made in the studies we reviewed on savings from improved rewind practices. ${ }^{10}$

\subsubsection{Comparing Rewinds with New High-Efficiency Motors}

The initial cost of purchasing a high-efficiency motor is at least three to four times greater than motor rewinding. Thus, the criteria for determining if rewinding is economical are (1) the cost difference between rewinding and a high-efficiency motor and (2) the difference in energy costs between new and rewound motors, which depends on the extent of core damage in the rewound motor.

The Pakistan study found the rate of return for the purchase of a high-efficiency motor instead of rewinding to be in the range of $16-115 \%$ for a 50 -hp motor. For an average 4000 hours of annual usage, the simple payback is estimated at three years.

The Thailand study conservatively assumes there is no degradation in the core due to rewinding and that there is a $4 \%$ efficiency difference between the standard, rewound motor and a new, high-efficiency motor.

As shown in Table 2.7, the CCE of efficiency gains through the application of high-efficiency motors is only slightly below the cost of avoided generation for motors above 500-hp or between 20-hp and 49-hp. Even though it is cost-effective from a societal perspective to replace the larger than 500-hp motors with a high-efficiency motor, most industrial users will probably prefer to keep such a large motor and have it rewound due to the high initial cost of large highefficiency motors. In addition, improved rewinding practices, which include the monitoring of core losses before and after the rewinding process, can improve the cost-effectiveness of rewinding.

The contrast between the Thailand and Pakistan results shows that assumptions regarding efficiency losses in rewinding strongly affect the economies of high-efficiency motors relative to rewinding.

\footnotetext{
${ }^{9}$ However, if the windings are not heated in an oven but instead manually removed without benefit of loosening through heating (as is common in Thailand), efficiency losses in developing countries could be lower than in industrialized countries. The careful removal of windings by hand may prevent incremental core damage.

${ }^{10}$ In India, due to problems with rewinding, sizing, maintenance, and phase balance, an energy loss of $7 \%$ is estimated. However, the amount attributable to rewinding is not broken out. The study estimates that correction of these problems can lead to a peak generation savings of 2.9 to $4.7 \mathrm{GW}$ in $2004 / 5$, which equals to $1.5 \%$ of projected generating capacity.
} 


\begin{tabular}{|c|c|c|c||}
\hline Table 2.7 & \multicolumn{4}{|c|}{$\begin{array}{c}\text { Cost-Efrectiveness of New, High-Efriciency vs. Rewound } \\
\text { Motors in Thailand }\end{array}$} \\
\hline $\begin{array}{c}\text { Size Range } \\
\text { (hp) }\end{array}$ & $\begin{array}{c}\text { Incremental Cost } \\
\text { (\$/avg motor) }\end{array}$ & $\begin{array}{c}\text { Savings } \\
\text { (kWh/avg } \\
\text { motor) }\end{array}$ & $\begin{array}{c}\text { CCE } \\
(\mathbf{C} / \mathrm{kWh})\end{array}$ \\
\hline $0-4$ & 180 & 219 & 10.8 \\
\hline $5-19$ & 635 & 988 & 8.4 \\
\hline $20-49$ & 1760 & 5107 & 4.5 \\
\hline $50-124$ & 4305 & 8580 & 6.6 \\
\hline $125-499$ & 10,175 & 19,531 & 6.8 \\
\hline $500+$ & 37,660 & 108,438 & 4.6 \\
\hline
\end{tabular}

- Assumes a $10 \%$ discount rate, 15 year lifetime.

Cost of avoided generation $=4.9 \mathrm{C} / \mathrm{kWh}$ (assuming $14 \% \mathrm{~T} \& \mathrm{D}$ loss)

\subsection{Conclusion}

The studies indicate that replacing a failed standard-efficiency with a high-efficiency motor is likely to be cost-effective for all but the smallest motor sizes. The technical potential for electricity savings is estimated at $1.5 \%$ to $4.7 \%$ of total industrial electricity use. In India, estimated savings from two-speed motors and high-efficiency motors are equal, or $2 \%$ of motor electricity use. The savings from improved rewinding of motors are uncertain, but probably significant in many cases. Since multiple rewinding is much more common in devaloping countries than in the industrialized countries, efforts to improve rewinding practices are important. 
Figure 2.1 Electricity Use by Various Sized Industrial Motors in Three Developing Countries

India

Annual Electrialty Usage in TWh

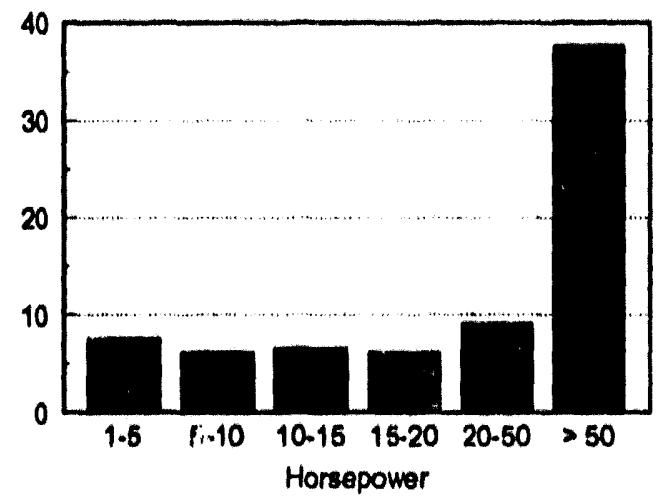

Brazil

Annual Electricity Usage in TWh

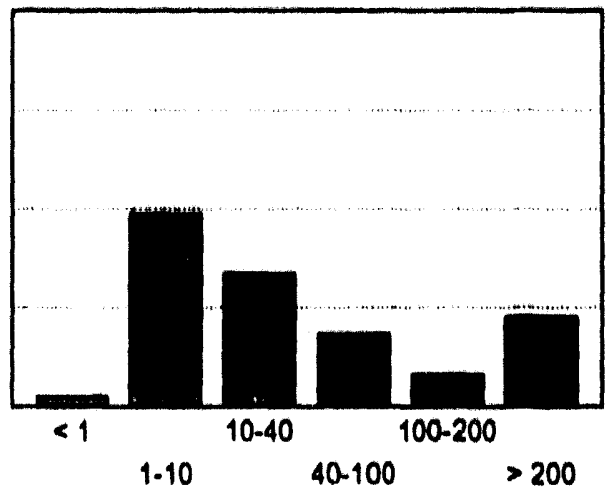

Thailand

Annual Electriclty Usage in TWh

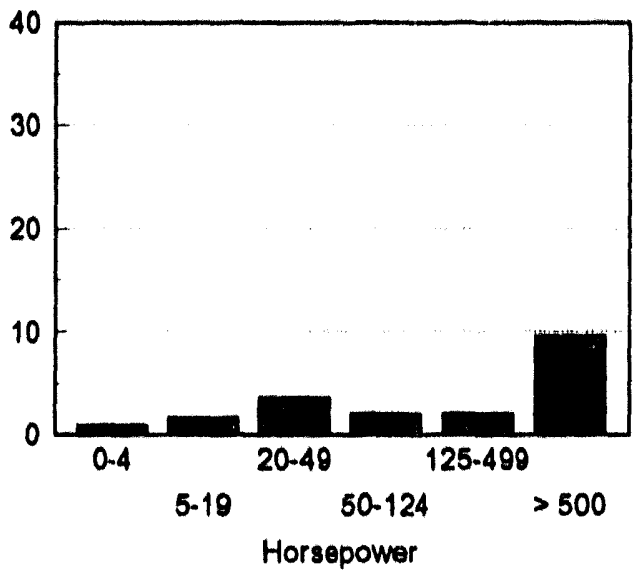




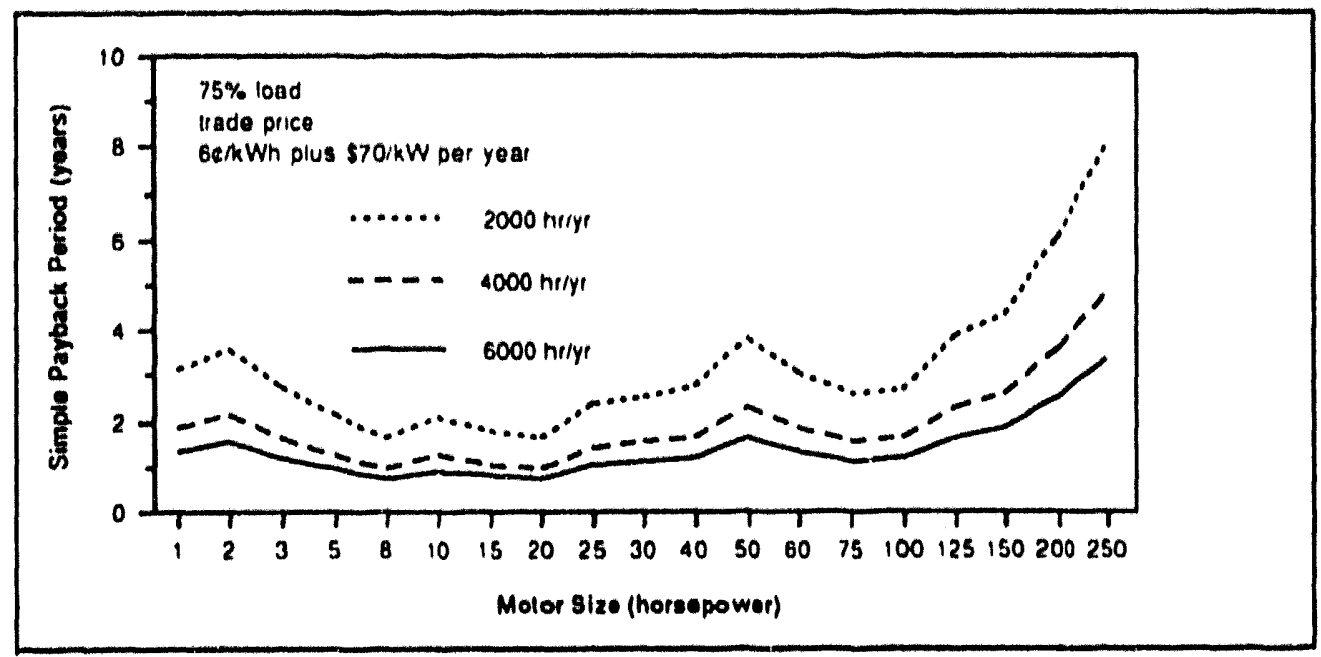

Figure 2.2. Simple payback times for new high-offlcienoy totally enclosed, fan-cooled (TEFC) motors ve. now standard TEFC motors as a function of motor alze and annual operating hours. The efflclencles used are an average of elght manufacturers' officlencies for 1,800-rpm molors.

Source: Nadol ot al., 1991

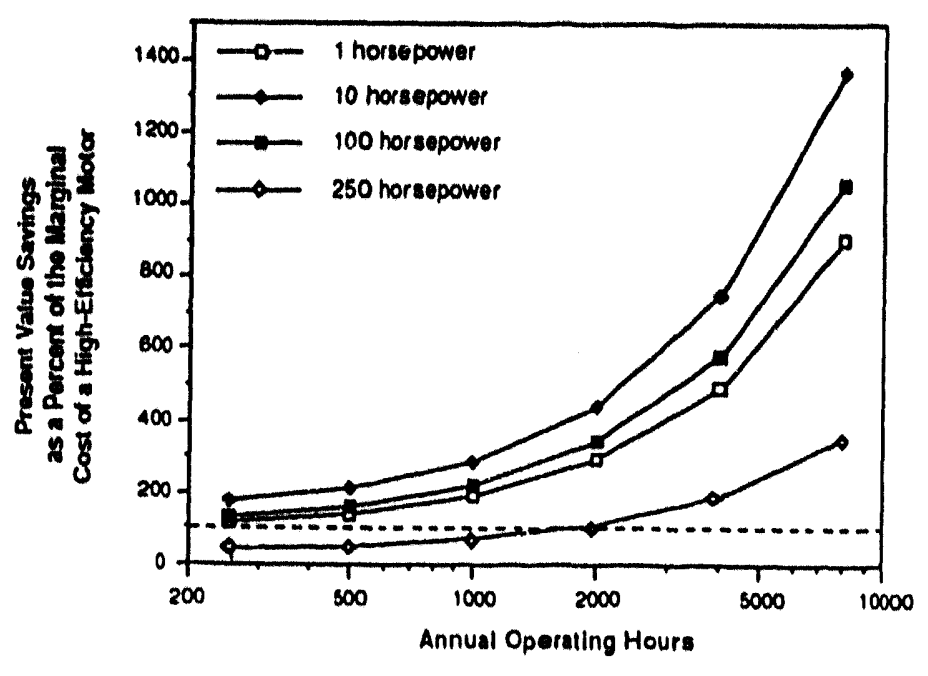

Figure 2.3. Present-value savings from high-eftlciency motors compared to the marginal cost of high-efflclency motors relative to standard-efficiency motors as a function of motor size and annual operating hours. Assumptions: 1,800.rpm TEFC motors; $75 \%$ load; $15-y e a r ~ l i f e$ and $7 \%$ real discount rate; energy and power savings are valued at $\$ 0.06 \mathrm{kWh}$ and $\$ 70$ per $\mathrm{kW}$ year; demand coincldence factor of 0.75 . Highefficiency motors are cost-effective from a life-cycle cost perspective whenever the present-value savings exceed the marginal cost of a high-officiency motor (I.e.. whenever present-value savings exceed the $100 \%$ line in the graph). Note that the struoture of the demand charge makes for a favorable present value even for motors with low operating hours.

Source: Nadel et al., 1991 


\subsection{POTENTIAL ENERGY SAVINGS THROUGH OTHER SYSTEM IMPROVEMENTS}

A motor is just one component of a motor system, and most of the energy losses occur outside the motor itself. By designing a motor system specific to the work that needs to be accomplished, energy losses are minimized. For example, motor-driven fan and pump systems that are designed for maximum efficiency can often reduce energy use by $50 \%$ or more from traditional designs. It is critically important to overall efficiency that the system be configured to optimize interactions between the individual components. For example, systems that operate on variable load could perform more efficiently if controls were installed to modulate motor speed. Common problems which reduce performance include: Oversizing of motors and motor components, poor power factor, and inefficiently designed pumps, piping systems, fans, air compressors, and gearbox components.

Existing inefficient systems can be improved to achieve substantial energy savings, although the lack of field data in both industrialized and developing countries makes quantifying the potential savings difficult. A field survey conducted in India by Tata Energy Research Instifute found that the efficiency of motors in the field was 4-13\% lower than manufacturer ratings for new motors due to problems with sizing, maintenance, phase balance, and rewinding (Anand and Kothari, 1990). The cost of remediating these problems, relative to standard practices, is usually very low. The India study estimates the CCE is only $1 \mathrm{c} / \mathrm{kWh}^{1}$ and that these measures may be applicable to $80 \%$ of the Indian motor stock. Another analysis for India estimates potential electricity savings of $12 \%$ to $13 \%$ for a combination of measures including improved motor sizing, power factor correction, correcting core damage from improper rewinds, phase balancing, and maintenance measures (Dutt, 1991).

To date, most drivepower efficiency programs have focused on the promotion of high efficiency motors, ignoring other system components for efficiency gains. In developing countries, where limited capital and hard currency make the purchase of high efficiency motors more difficult, other system improvements can save more energy than energy efficient motors, often at lower cost. Most of the information available on systems savings potential in developing countries applies to India and Costa Rica, although experience in the U.S. and limited data from Brazil, Pakistan, and Thailand indicate that relatively simple system improvements will yield substantial energy savings in most countries

\subsection{Reducing Oversizing in System Design}

Oversizing of motor system equipment is a common design practice in both developing and industrialized countries for it accommodates production expansion and provides a safety margin

'This assumes improved sizing and operation and maintenance measures have a simple payback of one year; that the average life of these measures is five years; and that the typical load is $60 \%$ with 4,200 part-load hours. The incremental cost of the measures is equal to the value of one year of $\mathrm{kWh}$ savings at $3.9 \mathrm{cents} / \mathrm{kWh}$. 
for the heaviest loads. Oversizing is even more prevalent in developing countries due to problems with power fluctuations, phase imbalance, and low voltages. Given these constraints, oversizing is often a reasonable design strategy. Because electricity costs are a relatively small fraction of total costs in most industries, design engineers have little incentive to change traditional practices.

Oversizing can lead to energy losses from part-load operation, poor power factor, and excessive throttling. Figure 3.1 illustrates how the efficiency of a squirrel-cage induction motor varies with the load. The efficiency of most motors is the greatest at $75 \%$ load, with a rapid drop-off in efficiency below 25\% $1040 \%$, depending on motor size. (High-efficiency motors better maintain their efficiencies across a range of loading.) If a motor is oversized relative to its typical use, it will frequently operate at low load and hence low efficiency. With improvements in electricity supply, a motor should be sized to operate at least at $50 \%$ of its rated load most of the time; a modest sizing margin can then offer the flexibility plant managers may want while maintaining energy efficiency.

\subsection{Improving Power fiactor}

When the load on a motor is below the full load rating of the machine, then power factor also falls below its full value. A three-phase motor typically operates at a power factor of 70-95\% at full load, but can be as low as $10 \%$ at no load. Low power factors compromise the efficient operation of an electrical supply system by causing increased losses in conductors, a reduction in system capacity, and higher voltage drops along conductors. There is a linear drop-off in system capacity with decreases in the power factor; for example, a $1000 \mathrm{kVA}$ transformer supplying electricity to a system with $70 \%$ power factor will only supply $700 \mathrm{~kW}$.

If the power factor is corrected, less current flows in the electrical conductors for a given delivery of power, causing an increase in the available capacity of the conductors. Another

\footnotetext{
2Power factor is an important characteristic that determines the efficiency of electricity use by a motor. It is defined as the ratio of real power (in kilowatts or kW) to apparent power (in kiloVolt-Amperes or kVA) drawn by the motor. Apparent power (KVA) is the vector sum of two components, the real (active) power (kW) and the reactive power (kVAr). The active component is responsible for the torque and work performed by the motor; the active part of the current is small at no load and rises as the load grows. The reactive component creates the rotating magnetic field; this component is almost constant from no load to full load, as is the magnetic field. Although the reactive component does not perform useful work, it is required to excite the motor and must be supplied by the power network. Induction motors are inductive loads and so operate with a power factor less than one; the current is delayed in time with respect to the voltage, so motors operate with a "lagging" power factor. Since power factor is a measure of the relative demands of active and reactive power of the motor, it increases with motor loading. The power factor associated with motors and other linear loads, where the current is displaced in time relative to the voltage, is known as the displacement power factor. In the case of non-linear loads (such as electronic VSDs, electronic ballasts, and computers), harmonic currents are produced that add to the total current (and KVA) without adding to the real power, so the overall power factor is reduced even though the displacement power factor of such loads is usually very high. Thus, both displacement and overall power factors must be evaluated to determine proper corrective action.
} 
benefit from power factor correction is a reduction in cable and transformer losses from resistive heating. Reducing these losses results in lower voltage drops and improved power quality; this reduces the need for a high margin of safety through oversizing motors that would otherwise be necessary to protect against bad power quality.

In developing countries, many industrial customers do not correct their low power factors. In Pakistan, the average power factor of industry is only 0.75 . In Nicaragua, $30 \%$ of large industrial electricity consumers operate with a power factor below 0.85 (Lewis, 1992). For several hundred industrial facilities audited by the Energy Conservation Center of Thailand, average power factors were found to be between 0.7 and 0.9 (IIEC, 1993). National electricity companies must supply the reactive power that these low power factor loads require, which contributes greatly to transmission and distribution losses.

The displacement power factor can be improved by installing capacitors or by operating a large synchronous motor in leading power factor mode in order 10 supply the reactive power consumed by induction motors. The capacitors can be installed in a distributed manner with capacitors on each motor, thus correcting power factor at the source, or in a centralized manner with capacitor banks installed at locations in the industrial plant. The greatest loss reduction is achieved for capacitor installations that are closest to the source of the low power factor (distributed installations). In the U.S., installed dispersed capacitors cost \$20-30/kVAr, while central capacitor banks cost \$50-75/kVAr (Nadel et al., 1991). In developing countries, capacitor costs are similar, though import tariffs and other country-specific factors may affect prices. For example, power factor correction in Pakistan costs only \$9-18/kVAr, much less than the cost of imported distributed capacitors in Nicaragua of around $\$ 31 / \mathrm{kVAr}$. For low power factors caused by harmonics, inductive or inductive/capacitive filters can be used to reduce harmonic current levels.

When consumers improve their power factor, reductions are realized both in their energy bill and in the fines assessed for operation with a low power factor. ${ }^{3}$ The monetary savings from avoiding the penalties are typically more valuable than the energy savings from power factor correction. In the U.S., typical paybacks for dispersed capacitor power factor correction are less than a year for power factor penalty avoidance, five years for reduced resistive lossis, and 9 months from combined savings (Nadel et al., 1991). In Nicaragua, paybacks solely for fine elimination are as short as 4 months (Lewis, 1992). In Pakistan, power factor correction has a combined payback of less than a year. The Pakistan report also estimates that if the average industrial power factor is improved from $75 \%$ to $95 \%$, then $3.4 \%$ of the electricity supplied to industry would be saved. An increase in power factor to just $85 \%$ in 2005 would add up to a projected saving of $1440 \mathrm{GWh}$ and $230 \mathrm{MW}$ of avoided baseload generating capacity. In sum, power factor correction is a simple measure with a fast payback, with the combined savings from energy and fine elimination typically less than a year.

\footnotetext{
'Electricity companies in many developing countries penalize consumers whose power factors are below a threshold level, typically in the range of $80-90 \%$. The fine is usually $0.5-1 \%$ extra on the electricity bill for every percentage point below the threshold level.
} 


\subsection{Motor Drive Speed Controls}

In the U.S., speed controls are estimated to offer the greatest potential for energy savings in motor systems (Nadel et al., 1991). The limited evidence from developing countries indicates that the situation may be similar. In Pakistan, potential energy savings are estimated at $12.6 \%$ of motor energy use, nearly four times the savings projected through high efficiency motors. What may limit their use, however, is high initial cost; some speed controls are more costly than the motor itself.

Motor efficiency is generally highest at around $75 \%$ load, but the actual load commonly varies with season, temperature, and process demands. For example, a motor in a commercial cooling system may operate at full-load during the hottest days of the year, but at other times the load placed on the motor may be significantly lower, varying with the outdoor temperature and humidity. For all applications (such as fans and pumps) load theoretically varies with the cube $\left(V^{3}\right)$ of the air or water flow. When the flow in such systems is reduced by $20 \%$, the load on the motor is reduced by nearly $50 \%$.

To meet load changes, the output of motor-driven equipment has traditionally been adjusted by employing dampers, throttling valves and by-pass systems, which do not reduce the energy drawn by the motor. These methods are akin to driving a car with the accelerator floored and controlling speed with the brake. Other alternatives are available for motor system control to supply the required power without the loss of so much energy. As discussed in Section 2.6, multi-speed motors can be used where two, three, or four speeds are required For motor drives with two distinct operating conditions, pony motors can be applied. Beyond the motor itself are a variety of motor speed control technologies. The simplest ways to perform speed control are mechanical and electro-mechanical means such as gears and pulleys, multi-speed motors, eddycurrent drives and fluid couplings. More modern speed controls that allow efficient operation over a wide speed range are based on solid-state electronics such as voltage control, cycloconverter, voltage source inverter, pulse width modulation and slip power recovery techniques. Table 3.1 presents these control methods and lists their advantages and disadvantages.

Shaft-applied speed controls, which include mechanical, hydraulic, and eddy-current drives, are installed between the constant-speed motor shaft and the driven equipment. They are lower in efficiency than electronic variable speed drives (VSDs), bulky, and require regular maintenance. However, they are easier to understand and repair than VSDs and may thus have greater application in developing countries where labor costs are low and technical expertise may be limited. Because their efficiency is low relative to VSDs, analysts have not reviewed potential savings from increased penetration of mechanical control methods.

Electronic VSDs placed between the power supply and the motor can vary the speed of a motor from $100 \%$ or more down to very low speeds, thus saving electricity during part-load operation of the motor. Electronic VSDs employing a frequency inverter are the most sophisticated and 
popular type of motor-speed control in industrialized countries A study of New York state estimated average electricity suvings in appropriate applications to be $22.5 \%$ (Miller et al., 1989), and savings of $50 \%$ or more may be achieved. In addition to the direct electricity savings, electronic VSDs provide indirect benefits through improved equipment lifetimes (due to the soft-start capability incorporated into most VSDs and reduced wear due to lower speed operation), better process control and product quality, isolation of motors from the power line (providing limited protection from power failure and line voltage problems), and operation at higher speeds than standard line frequencies otherwise allow (Baldwin, 1989).

Electronic VSDs are available in most developing countries, though domestic manufacturing, where it exists, commonly relles on imports for the necessary electronic components. Prices of electronic VSDs are thus sensitive to customs duty and exchange rates. Electronic VSDs are manufactured in India and Brazil by national companies as well as by multinationals. Some of the companies produce relatively modern motor drives such as pulse-width modulation type equipment containing imported power transistors and other advanced components.

Costs for inverter-based electronic VSDs have been decreasing steadily in the past few years and are anticipated to continue to fall, but they are presently still quite expensive. The price per hp of VSDs decreases as the size of the motor increases, and VSDs are thus most appropriate for larger motors. Based on prices quoted by the principal manufacturers in Brazil in mid-1990, sophisticated electronic VSDs cost around $\$ 900 / \mathrm{hp}$ at $10-\mathrm{hp}, \$ 400 / \mathrm{hp}$ at $50-\mathrm{hp}$, and $\$ 250 / \mathrm{hp}$ at 300-hp (Captzan, 1990). These prices are over twice the cost of similar electronic VSD models sold in the U.S. (Nadel et al., 1991) The high cost is attributed to duties on imported components, sales taxes, and the limited market. Nonetheless, approximately 1700 electronic VSDs were sold in Brazil in 1989 and the market was increasing by about 30\% per year. In Pakistan, duties range from 20\% to 30\% of the total cost of electronic VSDs. India represents an exception with costs for electronic VSDs nearly equal to costs in the U.S.

The combination of high initial costs and low electricity prices discourages the use of advanced motor-speed controls solely for the purpose of conserving electricity. In Pakistan, for example, small electronic VSD drives are not economical in applications with low horsepower or low annual operation. However, electronic VSDs can save substantial energy for the larger motors. The studies estimate that electronic VSDs could be suitable for applications accounting for $55 \%$ of motor electricity use in India, and $60 \%$ in Costa Rica. 
VSD Type

(Power, apead nnge)

Adrantuge

\section{ELECTROMECHANICAL CONTROL METHODS}

Geurn, Pulloge, ete.

Variablo Pulley sheavee

Ocarn

Chain

Friation Drives

Mull-npeed moton

Eddy-current drive $>0 \mathrm{KW}, 10: 1$

Fuid coupling drive $>0 \mathrm{~kW}, \mathrm{s:1}$
Low coal.

Low cout.

Low cout.

Low cost.

Operation at 2 to 4 nxed apeads.

Simple; relatively low cout; steplean apeed control.

Simplo; rolatively low cont; topleas upeed conirol.
Dlendrantene

Low power avinga; high maintenance coats.

stepped opeed control: lower off than ainglo-epeed motors.

Needa DC excitution (from AC power); low off. below sos raled upeed.

Low efliciency below 50 \% rated upeed.

\section{SOLID-STATE ELECTRONIC CONTROL METHODS}

Voliuge conirol

$<25 \mathrm{~kW}, 20-100 \%$

\section{Cycloconverter $>75 \mathrm{~kW},<30-50 \%$ \\ of supply frequency}

Voltuge source inverter $<750 \mathrm{~kW}, 100: 1$

\section{Current source Inverter} $>25 \mathrm{~kW}, 10.150 \%$

Pulse width modulation < $750 \mathrm{~kW}, 100: 1$

Sllp power recovery

$>500 \mathrm{~kW}$

$50-100 \%$

$50-150 \%$
Simple; low cout.

Can opente down to zoro speed.

High torque cupability.

Good efficiency: wimple circuit denign.

Regenerative braking: aimple circuit denign.

Oood power factor; low distortion.

VSD power rating lous than motor nuting.
Hurmonica; low lorqua; low eff; limited apeed range.

Complex circuit deaign; poor power fuctor at low apoeds.

No regen braking; problema at low upeed (< 10\%).

Poor power factor: poof performunce it low apeed.

No regenerative braking: alighily low off than VSI.

Can use only with woundrotor induction motors.

Sourco: CEBS, 1992. 
Depending on the initial cost of the electronic VSD, operating assumptions, and energy savings estimated, very different costs of conserved energy (CCE) can be derived. In India, the CCE is estimated at $2.4 \mathrm{C} / \mathrm{kWh}$ for $250 \mathrm{hp}$ electronic VSD4; using different assumptions, the CCE for electronic VSDs in Costa Rica is estimated at $18.7 \mathrm{c} / \mathrm{kWh}^{3}$. In 2005, total savings potential of electronic VSDs in Costa Rica is estimated at only $0.04 \%$ of projected sales, whille savings for the same year in India are anticipated to be $2.22 \%$. Larger polential savings were estimated for Brazil, with electronic VSDs estimated to potentially reduce motor electricity use by $8.4 \%$ of total 1988 electricity sales".

Although electronic VSDs have great potential for electricily savings, their penetration into the market in developing countries will likely be a slow process. Their high initial cost and sophisticated application are deterrents to rapid adoption, particularly where electricity prices are low.

\subsection{Improved Operation and Maintenance}

The efficiency of a motor system will decline without proper operation and maintenance (O\&M) lechniques, which include simple cleaning and lubrication, equipment maintenance (c.8., checking windings resistance and adjusting belt tension), and general inspection (i.e., assuring that the motor system components are appropriate to the task). A recent study of thousands of industrial motors in Brazil found that inadequate operational practices, such as bad cooling conditions, vibration, and incorrect maintenance procedures, were common (Soares, 1993). Such practices result in energy waste and reduced service life.

Improved O\&M procedures and lechniques include the following:

- Tum off equipment when not in use (subject to avoiding excessive stopping and starting).

- Use motors only when efficiently loaded (process permitting).

- Use fans and blowers instead of compressed air for process and space cooling.

- Repair damaged and/or missing insulation on hot and cold piping systems.

- Repair leaks and install air intakes in coolest locations for compressed air systems.

This anumen that a high officiency (95\%) motor operatew 5,000 hours each year; the VSD cost in \$262/hp; the peak coincidence factor in $60 \%$; the capital cout in $\$ 900 / \mathrm{hp}$ eaved; the life of the VSD is ten years (common for olectronics of this lype); and the average mavings in $22.5 \%$.

This figure in an average for all motorn over S-hp in wize, regardlesk of upplication and operating conditionn. The motor population needs to be diagegrogaled in order to find cout-effective applicationn. The Conta Rica utudy anumes an average motor aize of 22.6-hp, load factor of $75 \%$, and an average uvingh of $8 \%$ of the motor energy draw. The entimuled avinga is low, nearly $1 / 3$ tho avingu expected in India and Brazil. The average VSD cout for moton over $\mathbf{S}$ hp in entimated at \$4,100.

This asaumas that apeed controla are applicable to ono-third of total olectricity use by motors in the industrial woctor and that avinga average $25 \%$ per application. Thewe amumptions are rough guewsen. 
- Keep motors and other equipment clean and cool.

- Use high-quality lubricants.

One O\&M measure that can reap significant savings is the use of premium lubricants, which can increase efficiencies by $3 \%$ to 20\% in gear reducers, compressors, and motors. In Costa Rica, it is estimated that synthetic lubricants can save an average of $2 \%$ to $5 \%$ of electricity use and last four times longer than mineral oils. Although these lubricants cost four times more, the CCE is negative due to reduced O\&M costs: $-2.1 \mathrm{c} / \mathrm{kWh}$. The study estimates lubricants could save $3 \%$ of total energy used on $20 \%$ of the motor population.

Estimates of electricity savings from improved O\&M are few. In the U.S., one study found that proper O\&M can improve efficiencies $10 \%$ to 15\% (Ibanez, 1978); some energy engineers place this number as high as 30\%. The evidence is mostly anecdotal and typical maintenance practices are not well documented, particularly in developing countries. Simple techniques like turning off unused equipment, repairing damaged insulation, keeping equipment cool and clean, and using motors only when efficiently loaded offer inexpensive and effective means of improving the efficiency and extending the lifetime of the motor system. Further analysis of the savings potential from improved O\&M is warranted.

\subsection{Improved Mechanical Power Transmission}

Motor power is delivered to driven equipment by a mechanical linkage. Sometimes the motor shaft is directly coupled to the driven device, but typically power transmission equipment is utilized. In developing countries, the most common way for motor power to be delivered to a load is by the use of standard V-belts; loday there are many other options for power transmission. The Costa Rica study provides estimates on clectricity savings in this area.

Cogged V-belts allow greater flexibility and beller heat dissipation than standard V-belts?. They are applicable to motors below 10-hp in single-belt systems, and for multi-belt systems, motors up to several 1000 hp can use them. Cogged V-belts do not require sheave changes and O\&M is thus lower than for $V$-belts. Though the electricity savings estimated for Costa Rica are low, at $0.35 \%$ of projected GWh sales in 2005, the CCE is negative, at $-1.7 \mathrm{c} / \mathrm{kWh}$. The life and cost of cogged V-belts are estimated to be twice those of standard V-belts.

For motors above 7.5-hp, synchronous belts (also called timing belts or high-torque drive belts) can transmil drive power $4 \%$ to $10 \%$ more efficiently than standard V-belts. They are flat with rounded teeth and can be run at high velocities. Synchronous belts require that the sheaves be replaced with the bell and thus cannot be installed whenever a V-belt breaks. Synchronous belts last four times longer than V-belts. In Costa Rica, the CCE is estimated at $5.5 \mathrm{c} / \mathrm{kWh}$ and associaled electricity savings are $0.25 \%$ of projected GWh sales in 2005 . A primary drawback

\footnotetext{
'Unless otherwise noted, the information on cogged V-holts and synchronous belts is from the Costa Rica report.
} 
is that manufacturers are accustomed to standard V-belts and may not be receptive to change.

\subsection{Emciency of Driven Equipment}

Pumps, fans, and compressors use over half the drivepower energy of motor systems in the U.S. (Nadel et al., 1991). The data available on potential savings from pumps, fans, and compressors is for India, and possible savings in other countries must be inferred.

In India, an estimated $20 \%$ to $40 \%$ of industrial motor energy use is used by pump systems. There are a number of opportunities to improve the efficiency of pump systems, including use of high efficiency pumps, minimizing friction losses in piping networks, derating/replacing oversized pumps, and applying electronic VSD controls to vary fan and pump speeds. The National Productivity Council (NPC, 1991) found that new pump efficiencies in India have increased by $5-10 \%$ in recent years. High-efficiency pumps often cost the same as iese efficient pumps; where there is a cost prenium, it is modest (on the order of 5-10\%).

Much larger savings are available by minimizing piping-friction losses. NPC estimates a potential average savings in motor systems with pumps of $15-20 \%$, and provides an example of a typical application with a simple payback of less than three years. A common reason for wasted energy in pump and fan systems is oversizing of the driven equipment. NPC estimates potential savings of 5.10\% are available through the derating or replacement of oversized pumps in India. Selecting the equipment properly is time-consuming and difficult, and once it has been performed, it is seldom performed again. The appropriateness of the installed pumps or fans is rarely re-evaluated when a system is modified.

Combining a package of measures for India, it is conservatively estimated that $70 \%$ of industrial pump systems can benefit from cost-effective efficiency improvements and that average savings in these systems will total $15 \%$, with an average simple payback of three years 8 . Given a pump life of 20 years, this yields a CCE of $1.5 \mathrm{c} / \mathrm{kWh}$.

In India, fans and blowers account for over 10\% of industrial motor use. Opportunities to improve the efficiency of fan systems include: The use of high-efficiency fans, replacement of oversized impellers and fans, and reduction of friction losses. Often, just reducing fan speed will yield substantial savings. NPC indicates that even greater efficiency improvements are possible in fan systems than in pump systems; in addition to savings from reduced friction losses and derating/replacement of oversized fans, substantial efficiency improvements are possible from high efficiency backward-curved fan systems (10\% savings are typical when replacing radial fans, $20 \%$ savings when replacing forward-curved fans). The India study estimates the $\mathrm{CCE}$ for these measures is only $1.6 \mathrm{c} / \mathrm{kWh}$. In China, replacing a less efficient centrifugal fan

\footnotetext{
This analysis is for a 20 -hp pump operating at an average of $60 \%$ of full-load for 4,200 hours/year. Also, this assumes $60 \%$ peak coincidence factor and a $70 \%$ basecase pump efficiency (which incorporates the motor efficiency improvements discussed above).
} 
with a higher efficiency axial flow fan is estimated to reduce overall motor consumption by $1 \%$ to $2 \%$.

Many factories have compressed air systems that provide air for cleaning and industrial process applications. Compressors are typically located at central locations and supply lines distribute the compressed air throughout the plant. Compressed air systems are notorious for air leakage and associated energy waste. Many systems operate at higher pressures than needed, and maintenance of compressor systems is often less than adequate (for example, air filters are not cleaned). Furthermore, compressors are often oversized or inefficient. NPC found that energy savings of $20-40 \%$ are possible at low cost. The India study assumes a $30 \%$ energy savings, an average measure life of five years, and the basic operating assumptions made previously for pumps and fans. It estimates the cost per $\mathrm{hp}$ is $\$ 215$ and the CCE is $1 \mathrm{c} / \mathrm{kWh}$. Additional savings are possible from improved compressor controls and from the use of multiple compressors ${ }^{9}$.

\subsection{Summary of Savings from Other System Improvements}

The energy savings potentials from system improvements are difficult to quantify, but available evidence indicates they are substantial. Relatively simple O\&M procedures generally offer an inexpensive means for prolonging the life and improving the performance characteristics of motor systems, yet there have been few studies exploring this area for energy savings. Much more evidence is available for electronic VSDs. As an individual strategy, VSDs appear to offer the greatest potential for energy savings, but their high initial cost and sophisticated application are substantial obstacles to their adoption. For general system improvements (which include improved rewinding techniques), the India study estimates a $2 \%$ savings of projected GWh sales in 2005.

The results of 1,200 industrial audits in Brazil suggest that a bundle of nine no - or low-cost industrial electricity conservation measures ${ }^{10}$ would save $7 \%$ to $18 \%$ of electricity use in many industries. These measures apply to the industrial complex as a whole and are thus broader than the motor system alone, but many of the measures apply to motors. The Brazilian subsidiary of Goodyear implemented these measures and reduced electricity consumption per ton of output by $20 \%$ at its main tire factory in Sao Paulo.

\footnotetext{
With multiple compressors, when air requirements are low, a small compressor is used; when requirements increase, a medium-sized compressor is used; and when requirements are large, both compressors are used together. Such a system allows better matching of compressor power to the load, thereby avoiding part-load operation of compressors (as discussed previously, part-load operation can result in considerable energy waste).

${ }^{10}$ The nine measures are the following: Replacing oversized motors, replacing overloaded lines, adjusting or replacing overloaded transformers, correcting low power factor, correcting unequal current among different phases, reducing excessive peak loads, providing adequate protection, improving transmission systems between motors and subsequent equipment, and using more efficient lamps or light fixtures.
} 
As indicated in Table 3.2, the CCE of system improvements is often quite low, with many measures below $3 \mathrm{c} / \mathrm{kWh}$. It is important to be cautious, however, in comparing the CCE for different countries. Different assumptions are used for deriving C,CE and for estimating savings potentials. Thus, the India study finds the CCE of electronic VSDs to be only $2.4 \mathrm{c} / \mathrm{kWh}$, while the Costa Rica study calculates the CCE at $18.7 \mathrm{c} / \mathrm{kWh}$.

\begin{tabular}{|c|c|c|c|}
\hline Table 3.2 CCE and Sa & $\begin{array}{l}\text { tentials for } \\
\text { in Inc }\end{array}$ & $\begin{array}{l}\text { mprovements (Excluding } \\
\text { Costa Rica }\end{array}$ & h-Efficiency Motors \\
\hline \multirow[t]{2}{*}{ Measure } & $\mathrm{CCE}^{*}$ & $\begin{array}{c}\text { Savings as } \% \text { of } \\
\text { Projected GWh Sales in } \\
2005\end{array}$ & $\begin{array}{l}\text { Savings as \% of } \\
\text { Projected Generating } \\
\text { Capacity in } 2005\end{array}$ \\
\hline & \multicolumn{3}{|c|}{ INDIA } \\
\hline VSDs & $2.4 \mathrm{c} / \mathrm{kWh}$ & $2.22 \%$ & $1.41 \%$ \\
\hline Two-Speed Motors & $1.1 \mathrm{c} / \mathrm{kWh}$ & $0.76 \%$ & $0.57 \%$ \\
\hline Pump Systems & $1.5 \mathrm{c} / \mathrm{kWh}$ & $0.62 \%$ & $0.47 \%$ \\
\hline Fans & $1.6 \mathrm{c} / \mathrm{kWh}$ & $0.49 \%$ & $0.37 \%$ \\
\hline Compressors & $1 \mathrm{c} / \mathrm{kWh}$ & $0.34 \%$ & $0.27 \%$ \\
\hline \multirow[t]{2}{*}{$\begin{array}{l}\text { General system (sizing, } \\
\text { rewinding, etc.) }\end{array}$} & $1 \mathrm{c} / \mathrm{kWh}$ & $2.04 \%$ & $1.54 \%$ \\
\hline & \multicolumn{3}{|c|}{ COSTA RICA } \\
\hline Cogged V-belt & $-1.7 \mathrm{c} / \mathrm{kWh}$ & $0.35 \%$ & $0.25 \%$ \\
\hline Synthetic lubricants & $-2.1 \mathrm{c} / \mathrm{kWh}$ & $0.13 \%$ & $0.09 \%$ \\
\hline Sync. belt & $5.5 \mathrm{c} / \mathrm{kWh}$ & $0.25 \%$ & $0.18 \%$ \\
\hline VSDs & $18.7 \mathrm{c} / \mathrm{kWh}$ & $0.04 \%$ & - \\
\hline
\end{tabular}

* The discount rate is $10 \%$ for India and $12 \%$ for Costa Rica.

By optimizing system design, plant managers can capitalize on system synergies and high performance technologies. However, simple O\&M improvements may prove the least cost means of enhancing motor life and efficiency. The energy losses attributed to factors other than the operation of the motor itself can often be easily reduced through a variety of low- and nocost measures. Modifications to motor systems can undoubtedly offer considerable electricity savings in the developing world. 


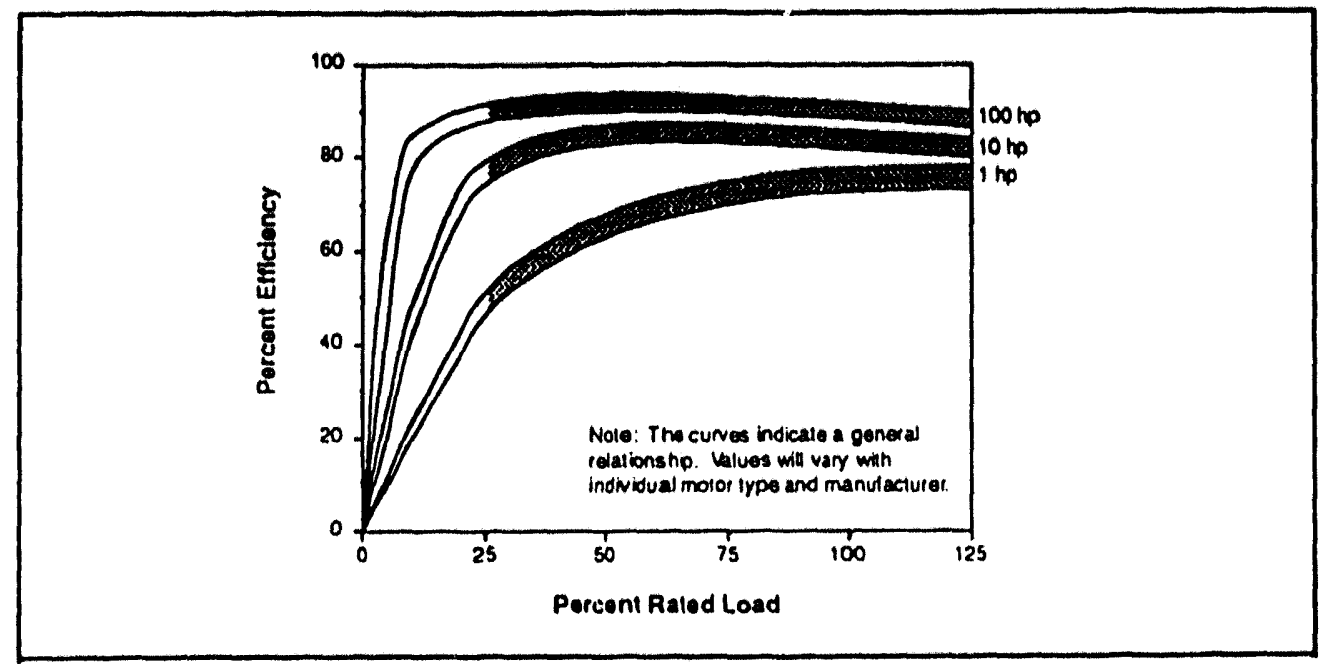

Figure 3.1. Typical efficiency ve. bad curves for 1,800-rpm three-phase $60-\mathrm{Hz}$ Design B squirrel cage induction motors.

Source: Nadel et al., 1991 


\subsection{POLICIES TO PROMOTE ENERGY EFFICIENT MOTOR SYSTEMS}

There are numerous measures that can improve the energy efficiency of motor systems in developing countries. Most of the available measures offer paybacks that are attractive from a societal perspective, but an array of barriers deter industries from undertaking them. Various types of policies and programs can help to overcome the barriers and thereby contribute to higher motor system efficiency. These policies can reduce the need for costly generating capacity additions, lower the probability of electricity shortages, help industries thrive in increasingly competitive markets, and reduce the environmental and social costs of electricity generation. The challenge facing governments is to foster communicution between the actors that have a stake in promoting efficient motor systems and to create a climate for investment where end-users have both the incentive and the means to implement efficiency improvements. Given that many developing countries have only modest programs in energy efficiency and limited resources to expand them, such programs should promote improvements offering the most benefits (energy and other) at the least cost.

\subsection{Determining Priorities}

To evaluate and prioritize efficiency strategies, policy-makers need to consider indicators such as cost of conserved energy, electricity generation savings, and avoided new generating capacity. Each country will require individual analysis that reflects the shape of its industrial sector, pricing and taxation policies, capability to produce high-efficiency motor system equipment, the avoided cost of electricity generation, and other country-specific features.

To evaluate least-cost electricity savings, one must look not only at the motor itself but at the larger system for potential efficiency gains. As emphasized in the previous sections, the efficiency of a motor system is comprised of more than the efficiencies of the individual parts; design and operating characteristics affecting the interaction between components enter fundamentally in the calculus. As Figure 4.1 illustrates, there are numerous junctures where improvements can be made. Some general improvements can benefit both the motor and the system it drives:

(1) Improving the quality of power both in the plant (through power factor correction, wire sizing, and load balancing) and in the supply system (through improved voltage regulation) reduces the need for the oversizing of components;

(2) Using proper operation and maintenance techniques can enhance performance and lengthen the lifetime of the components.

Though it is difficult to assess the potential electricity savings from measures to enhance general system performance, the estimates made thus far indicate large savings are available at costs well below the long-run marginal cost of electricity, and such measures often have benefits in addition to energy savings (e.g., longer equipment lifetimes). In India, general improvements relating to 
operation and maintenance, phase balancing, rewinding, and sizing have the potential to save an estimated $2 \%$ of projected motor electricity use in 2005, and represent the second largest area of electricity savings (see Figure 4.2).

The potential electricity savings from the increased penetration of higher-efficiency technologies for motors and other components also quite large. Despite their favorable life-cycle economics, high-efficiency technologies have yet to make significant inroads into the market in developing countries'. High-efficiency motors and properly rewound standard motors are obvious measures to target, though various other efficiency technologies are available, some at lower cost and with greater electricity conservation potential. As Figure 4.2 illustrates, high-efficiency technologies in India have the technical potential to reduce projected motor electricity use in 2005 by about $5 \%$. Variable-speed drives offer the greatest savings, followed by high-efficiency motors, twospeed motors, pumps, and fans.

The savings estimates presented thus far represent technical potential, in which all measures considered technologically feasible and cost-effective from a societal viewpoint are implemented. A variety of factors, however, dissuade consumers from making cost-effective investments in motor system efficiency, and actual savings will thus be lower than the technical potential. Policy-makers will need to address barriers to efficiency improvement to diminish the gap between technical potentials and actual savings.

\subsection{Barriers to Efriciency Improvement}

While barriers also exist in industrialized countries, they are exacerbated in the developing world by lack of information, a scarcity of skilled personnel, capital shortages, high import duties, and subsidized electricity rates. Given the difficult constraints facing industries in developing countries, an end-user's decision not to invest in energy-efficient motor systems often makes economic sense.

As in industrialized countries, electricity costs are usually a small share of the total operating costs of an industrial facility. In U.S. manufacturing, the average electricity costs are only $2.8 \%$ of the value-added (Ross, 1986). Since industrial electricity prices have traditionally been subsidized in many developing countries in order to promote industrial development, reducing electricity costs may be an even lower priority than for U.S. managers.

At the plant level, engineers may not know how to diagnose where efficiency opportunities lie or how to implement them. Some measures, like electronic VSDs, are relatively new and potential users may lack information about their performance or cost-effectiveness. This may raise concerns that installing new technologies could result in down-time or impede production processes. Compounding the information problem, there is often no standard method for

\footnotetext{
'High-efficiency motors comprise less than 5\% of new motors purchased in Thailand. This can be compared to the U.S. market where high-efficiency motor sales are around $20 \%$ of the market for motors above 20-hp.
} 
evaluating motor efficiency; motor manufacturers may use different test methods, and industrial consumers cannot then determine the relative efficiency of motors made by different manufacturers.

Even where end-users are aware of cost-effective measures, sensitivity to the first costs of equipment combined with a shortage of capital may prevent investment. Firms in the U.S. generally only invest in energy conservation measures that yield simple payback in two to three years. In developing countries, the required payback time is usually even shorter due to high interest rates, high and/or uncertain inflation rates, and lack of experience with these kinds of investments. ${ }^{2}$ In addition, the cost differential may be higher in developing countries for energyefficient equipment, which is commonly imported and subject to high duties. A negative feedback can result where the limited availability of energy-efficient equipment leads to high cost, which in turn leads to low demand. Even in countries like India where the larger domestic manufacturers produce high-efficiency motors, the duties on imported components lead to higher motor prices. Small-scale manufacturers that commonly produce cheaper and lower efficiency equipment often have a competitive edge over the more efficient and expensive motors produced by the larger firms.

There is a divergence between the criteria that industrial consumers use to evaluate efficiency investments and those applied by utilities to evaluate comparable investments in electricity supply. For example, the simple payback of the investment on a package of measures to improve the efficiency of a 20-hp pumping system in India is three years (see Section 3.6). This would be seen by industies as a relatively long payback period and it is unlikely that a firm would make the investment. Using a public sector discount rate of $10 \%$, however, the CCE for a pump life of 20 years is 1.5 cents $/ \mathrm{kWh}$, well below the long-run marginal cost of electricity supply. The investment from a societal perspective is therefore cost-effective and would promote an efficient use of resources.

Altiough the barriers to higher motor system efficiency are formidable, a wide range of approaches involving various actors are available to help overcome them. In our discussion of these policy alternatives, we summarize the experience in North America and highlight those areas of most significance for developing countries. First, however, we discuss some key changes that are re-shaping the general environment in which industries in developing countries make investment decisions.

2 A study of investment in encrgy conservation by industries in a number of developing countries conducted for U.S. AID concluded that "the simple payback requirements of most companies appear to be very short and in all countries, many projects with paybacks of less than 1 year and very small investment requirements have been rejected (RCG/Hagler, Builly, Inc., 1989). In addition, the majority of energy conservation measures identified and implemented have paybacks of 1 year or less." 


\subsection{General Policles Affecting Industrial Investment Decisions}

In many developing countries, government policies regarding the price of electricity, trade and investment, and domestic competition have dampened progress in industrial energy efficiency in general. Competitive processes have been inhibited by such factors as the regulation of profits, restrictions on licensing for new companies, and maintenance of monopolies by stateowned enterprises. Price controls restrict the amount of profit that an industry receives, inhibiting capital formation for modernization. Entry into the market has been limited by restrictive licensing requirements and import barriers that result in reduced competition. Staterun enterprises in developing countries have commonly been inefficiently operated and impervious to competitive influences.

All of these factors have tended to lessen management interest in improving productivity and constrained investment that might lead to higher energy efficiency. In recent years, however, more and more countries have embraced "free market" policies that give industry better access to capital and improved technology. While this evolution will not, in itself, remove all the barriers to conservation, it does provide more incentive for companies to increase the efficiency of their production processes.

\subsubsection{Energy Pricing}

In recent years, electricity pricing policies have undergone considerable change in many countries in response to fiscal pressures and the urging of international lending institutions like the International Monetary Fund and the World Bank. Many developing country governments have reduced or, in some cases, eliminated industrial electricity subsidies as a result of these pressures. To cite one important example, in January 1993, the Chinese government announced plans to gradually remove the subsidized electricity quota for state-owned factories (China Daily, 1993). Historically, China's state enterprises have received substantial subsidies on purchases of electricity; some industries pay only about half the average cost of generation. The removal of electrici.y price subsidies will stimulate interest in the more efficient and careful use of electricity, but factors such as capital shortage may still prevent action.

\subsubsection{Trade and Investment Policy}

Import duties in developing countries have historically been high in order to both raise revenue and protect domestic industries. Since many countries rely upon imports for supplying motor system components (particularly for the high-efficiency equipment), duties can raise the price of imported energy-efficient equipment considerably. When both standard-and high-efficiency equipment are imported, the duty raises the price differential between the two. In contrast, imported equipment specific to electricity supply is typically free of duty. From a national economic perspective, import duties on energy-efficient equipment thus contribute to underinvestment in energy efficiency relative to energy supply.

The general trend in many developing countries toward lower import duties for all goods will 
reduce the price of energy-efficient equipment for motor systems (especially if global trade negotiations are successfully concluded). In some countries, the resulting higher demand may then encourage domestic manufacturers to begin production of higher efficiency equipment. Where the domestic industry is just beginning to produce such equipment, the situation may warrant maintaining import duties for a time. Selective reduction of duties for energy-efficient equipment is also a policy option that some countries have implemented.

Joint ventures between local and multinational companies are prime vehicles for the transfer of new designs and production techniques, as well as sources of capital for new production facilities. In the past, the discouragement in many developing countries (either explicitly or by daunting bureaucratic procedures) of joint ventures has limited the introduction of new technology. Joint ventures are now being encouraged and may prove important in increasing investment to produce energy-efficient equipment. In China, for example, much of the more efficient fans, pumps, and other motor-driven equipment is produced by joint ventures between Chinese and foreign companies that were established to produce for domestic and export markets. Although the products from joint ventures are often targeted for Western markets (to earn hard currency), sales in the domestic market may grow with time.

While energy pricing and other economic reforms will contribute to greater interest in efficiency improvement, they will not by themselves overcome all the barriers to cost-effective conservation. Such reforms will not, for instance, address the gaps in information on energyefficiency technologies that are particularly prevalent in the developing world.

\subsection{Education Programs}

Education programs to increase awareness of the value of motor system efficiency and develop expertise to implement measures can take the form of seminars and courses, publications, databases on efficiency technologies, and well-publicized demonstration projects. In the OECD countries, the focus of education programs has been on technologies like high-efficiency motors, VSDs, and power factor correction. While such topics are also relevant in developing countries, education programs should also encompass less capital-intensive improvements, emphasizing basic information on motor system design, O\&M, motor sizing, rewinding practices, and use of multi-speed motors as a low-cost alternative to VSDs.

Information dissemination in the form of publications, brochures, posters, and other communication tools can enhance awareness of energy efficiency options. While governments in developing countries have conducted information dissemination campaigns on energy efficiency through advertisements in newspapers, magazines, radio and television, it is not clear to what extent motor efficiency has been promoted. In North America, many government agencies, utilities, trade associations, and manufacturers have conducted information campaigns on motor efficiency. For example, BC Hydro has distributed a series of publications on motor efficiency, from small brochures on specific topics such as compressed air systems to more detailed booklets on such topics as "High-Efficiency Motors" or "Adjustable-Speed Drives." 
Recently, a collaboration between India's National Productivity Council (NPC) and the Center for Energy and Environment Studies (CEES) of Princeton University (U.S.) produced a "technology menu" for motor drive systems (NPC and CEES, 1993). Intended as an aid for designing and implementing industrial energy efficiency improvement programs and projects, the set of materials in the "meilu" is a concise, user-friendly, "first-stop" source of reliable data and analyses relating to the performance and costs of energy-using technologies, with an emphasis on options for improving efficiency. The "menu" contains entries on both components (motors, pumps, fans, etc.) and systems.

Seminars and training courses can build upon information dissemination campaigns and help upgrade professional skills. In the U.S., the North Carolina Alternative Energy Corporation (a non-profit organization affiliated with government agencies and private electric utilities) has offered a unique program to train energy managers and to guarantee their salaries. If the energy manager fails to recover in energy savings at least the amount of his/her salary, NCAEC will pay the difference. Thus, organizations can hire energy managers at no financial risk. After the first two years, NCAEC found that the average energy manager saved twice his/her salary, and the NCAEC had to pay less than 3\% of the total salaries guaranteed by the program (Nadel, et al., 1991). In addition to professional education, there is a need to place greater emphasis on motor system efficiency in the engineering curricula of universities and technical institutes. Particular emphasis should be placed on proper system design and other aspects of process optimization.

Less extensive training could be given to key personnel at all points in the distribution chain from distributor to dealer to salesperson. A study in the U.S. (Fryer and Stone, 1993) found that distributors are the market participants best positioned to promote motor efficiency, particularly since the replacement of a failed motor often requires fast turn-around.

While important, education programs by themselves are not likely to bring about much efficiency improvement. Rather, they provide a necessary foundation upon which a broader, more comprehensive program may be constructed. Overcoming the many barriers to conservation will require a multi-faceted response, whereby the industrial sector is provided the information, means, and institutional support to implement efficiency measures.

\subsection{Motor Efficiency Information}

Standardized rating of motor efficiency is a prerequisite to the evaluation of alternative products, establishment of efficiency requirements, promotion of high-efficiency equipment through incentive programs, and assessment of program performance.

A variety of test procedures for motors are used in different parts of the world. In any given country, establishing a testing regime will require standardized testing protocols, independent testing facilities, and a monitoring system to ensure manufacturer compliance. The testing protocol should evaluate both the average and minimum efficiency of a particular model. 
In North America, a motor labeling standard, mandatory for members of the National Electrical Manufacturers' Association (NEMA), is widely observed by manufacturers for motors in the 1-125 hp size range. In contrast to appliances, however, new motors are rarely seen by customers prior to purchase, so motor labels have limited value in the buying decision. Labels may be somewhat useful in the used motor market by telling purchasers the motor's nameplate efficiency when the motor was new.

Unlike labeling, efficiency information in catalogs is critically important in the new motor market. However, even in the U.S. this information may not be easily accessible. A review of catalogs from six major motor manufacturers found only one manufacturer that listed efficiencies for all its motors; three listed efficiencies in an appendix or supplement; one provided efficiencies for only its high-efficiency motors; and the last provided no efficiency information whatsoever (Nadel et al., 1991).

\subsection{Motor Emelency Standards}

Standards can be an effective means of moving the market for new motors toward higher efficiency. Standards can take the form of voluntary agreements between manufacturers and the government or mandatory laws that manufacturers must meet. Voluntary standards are typically in the form of guidelines established by manufacturers' associations. For example, NEMA published a standard in 1989 that listed the nominal and minimum efficiency a motor must meet or exceed in order to be designated as "high-efficiency." The NEMA standard (known as Table 12-6B) was met by nearly all high-efficiency product lines and even by some standard-efficiency motors. Voluntary agreements on some products were negotiated in Japan and Germany in the 1980s, and were in the process of being negotiated in Brazil in 1991, where the major manufacturer of small- and medium-size motors endorsed the phasing out of standard-efficiency motors.

The U.S. recently became the first industrialized country to adopt strong mandatory minimum efficiency standards for new motors. The Energy Policy Act of 1992 sets minimum efficiency levels for major types of motors in the range of 1-200 hp. The standards, which are based on minimum efficiency values developed within the motor industry, vary with motor size, speed, and enclosure type (Geller and Nadel, 1992). As an indication of the stringency of the standards, the minimum efficiency levels meet and generally exceed the levels that NEMA had specified in 1989 in order for motors to be designated as "high-efficiency." They will eliminate $80 \%$ of the currently sold motors from the market, but manufacturers will have five to seven years from the date of enactment before the standards take effect. The legislation also requires the U.S. Department of Energy to consider adopting efficiency standards on motors under $1 \mathrm{hp}$ in size.

China has a voluntary standard for motors and other equipment. The Ministry of Machinery and Electronics regularly publishes lists of efficient and inefficient equipment to encourage removal 
of the latter from the market. In some cases, these inefficient models have in fact been eliminated, but in others, manufacturers have continued to produce the older equipment trusted by users.

The impact of standards obviously depends on how stringent they are relative to the market and how well they are enforced. At a minimum, standards remove the least efficient models from the market. At a imaximum, standards may push manufacturers to introduce new designs, perhaps requiring retooling in factories and some capital investment.

In the developing country context, stringent mandatory standards may face several problems. One is concerm about the ability of small manufacturers to meet the standard. These companies typically have less access to capital for upgrading production than larger firms that may be connected to forelen companies. There is also the issue of enforcement of standards in situations where there are many small manufacturers. One option would be to introduce scandards only on the larger motors that are not made by small manufacturers. A general concern is that by removing relatively cheaper molors from the market, standards will make if more difficult for some consumers to purchase new motor, and encourage rewinding instead. This problem could be lessened through utility incentive programs.

\subsection{Technical Assistance Programs}

Since technical expertice in industrial firms in developing countries is often in short supply (or over-burdened with managing normal operations), programs that provide technical assistance can be extremely valuable in identifying and evaluating opportunities for improving motor system efficiency in both existing and new applications. Industrialized countries could support this effort through training of energy auditors and assisting in the development of on-site evaluation tools. Assistance can be provided to consulting engineers and motor salespeople as well as to the end-users.

The time required 10 assess the costs and benefits of efficiency measures can be greatly reduced through calculational aids. In Canada, Ontario Hydro distributes a free spreadsheet program to motor distributors and customers that calculates the energy savings, demand savings, retum on investment and simple payback of high-efficiency versus standard motors. In the U.S., similar software tool called MotorMaster can be purchased for \$50/year, which includes annual updates. Computer programs are available from a variety of sources in the U.S. and Canada on VSDs, pumps, fans and other components. In developing countries, software tools may prove useful to large industrial users, but small users will require simpler tools.

On-site assessments and follow-up assistance entail a much higher degree of interaction and expense, but have the advantage of being site-specific. Free energy audits have been offered for many years by a variety of entities (utilities, government entities, manufacturers, trade associations, international assistance programs) in both industrialized and developing countries. Where appropriate, programs should include detailed engineering design studies to determine the 
feasibility of promising efficiency projects identified in the audit. This would be an appropriate entry point for financial assistance (e.8. rebates of loans) 10 implement the audit recommendations. Process design studies may also be offered to frms that are building a new factory or expanding an existing factory. This type of program requires the abllity to move quickly in order to fit the customers' schedules.

Brazil's national conservation program, PROCEL, has sponsored a program to identify no- and low-cost electricity conservation measures for motor systems and other end uses. A savings of 8.15\% of electricity use was identified by the audits, though measures accounting for only $30 \%$ of the identified savings potential were usually implemented (Lattore, Nobre, and Burgoa, 1990).

The experience with energy audits in the U.S. as well as in several developing countries shows that implementation rates are much higher for recommendations with rapld paybacks than for measures with moderate or high costs. For example, an evaluation in the U.S. for one program found that a measure with one year simple payback was ten times more likely to be implemented than a measure with a two year simple payback (Gustafson and Peters, 1987). To encourage a higher rate of implementation of cost-effective measures, it is necessary to link lechnical assistance programs with financing or other incentives.

\subsection{Incentlve Programa}

The purpose of incentive programs is 10 lower the cost 10 end-users of making investments that improve energy efficiency. Incentives include rebates, low-interest loans, and lax incentives. The justification for incentives from a utility or societal perspective is that it is often less expensive to pay customers to improve efficiency than to provide the equivalent electricity supply over the llfetime of the equipment. In North America, many utilities have offered incentives for motor system efficiency as part of their industrial demand-side management programs.

\subsubsection{Rebare Programs'}

Rebates for high.efficiency motors are the most popular incentive for drivepower efficiency improvement in North America. As of 1993, over 100 utilities offered rebates for highefficiency motors. Rebales are typically about $\$ 10$ per horsepower. Program eligibility levels and rebate formulas vary with molor horsepower and sometimes with motor speed and enclosure type.

Most programs target new applications or situations where a new motor will replace a failed motor. A \$10/hp rebale covers much of the price difference between new standard- and highefficiency motors and, in sizes up to about $30 \mathrm{hp}$, the difference between rewinding and a new

'Adapled from Nadal a al. (1991). 
high-efficiency motor. Such a rebate covers only a small portion of the cost increment for replacing instead of rewinding in large motors (greater than $30 \mathrm{hp}$ ), and an even smaller portion of the price premium involved in replacing a working motor. The size of the rebate is critical to participation; the New England Electric System found that the participation rate for its rebate program quadrupled when incentives were increased.

Most motor rebate programs have received limited marketing and have had a modest impact on sales of high-efficiency motors. On the positive side, most programs have yielded inexpensive savings: $\$ .001-.005 / \mathrm{kWh}$ and $\$ 79.822 / \mathrm{kW}$ saved. While the average motor rebate program has had only limited participation, a few programs have reached a wider audience. Niagara Mohawk ran a pilot program during 1986 in which 33\% of targeted customers participated. The program focused on large industries with long operating hours, provided extensive personal attention, offered a free computer assessment of costs and savings, and provided high ( $\$ 25 / \mathrm{hp})$ rebates sufficient to pay over half the cost of a new replacement motor in many applications.

Pacific Gas and Electric (PO\&E) achieved a 1.7\% participation rate in less than one year with its Energy-Efficient Motor program targeted at medium and large customers. Many additional customers were reached in subsequent years through a program that provided rebates for various measures including motors. This program was promoted through mailings and extensive personal contacts with eligible customers and motor dealers. The program also included procedures 10 qualify applications over the phone, so that when a motor failed, the customer could quickly purchase a new high-efficiency motor and still qualify for a rebate (Calhoun, 1984).

An alternative approach for dealing with failed motors has been used by Southern California Edison. That utility allows customers to receive rebates for a reasonable number of motors purchased for inventory stock. When an old motor fails, the new high-efficiency motor is already in the warehouse and can be quickly installed (Mayo, 1989). Several other utilities have adopted this policy.

The experience of BC Hydro (Canada) indicates the importance of rebates and incentives for vendors (Nelson and Ternes, 1993). After some eight years of education and promotional efforts, the market share of high-efficiency motors in British Columbia in 1988 was only 3.5\% (in part due to relatively low electricity prices). Most vendors did not carry high-efficiency motors in stock, and the required lead time for supply was often beyond the purchaser's time-frame. After three years of incentive programs (customer rebates and vendor incentives to encourage stocking and sales of high-efficiency motors), the high-efficiency motor market share had grown to over $60 \%$. There is speculation that a permanent market transformation has occurred, and that the rebate program may no longer by required to sustain sales of high. efficiency motors. This suggests a dynamic role for utilities, whereby intervention in the market may only be required for limited periods in order to affect permanent market transformation. Although the rebates covered much of the incremental cost of high-efficiency motors, the incentive programs were delivered at a levelized cost of only 1.2 cents ' $k W h$. To encourage purchase of the most efficient high-efficiency motors, the rebates are based on $\mathrm{kW}$ saved (in 
contrast to paying the same amount per hp for all units above a high-efficiency qualifying line). The utility also developed an educational booklet for customers, computer software for dealers and large customers to use to estimate energy savings, and a list of all dealers in the province supplying efficient motors. Program marketing emphasizes personal contacts between field representatives and large customers, consulting engineers, and motor suppliers. Many motor suppliers have actively promoted the program (Henriques, 1989). Ontario Hydro began a similar program for high efficiency motors several years later that has achieved a $40 \%$ penetration.

In the developing countries, rebates for motors (or other motor system equipment) are as yet untried to our knowledge. A program offering rebates is planned in Thailand that will pay $100 \%$ of the incremental cost of high-effici icy new motors to the customer. Customers who replace (rather than rewind) old motors and who deliver their old motor to be scrapped will receive a financial reward. Motor distributors and vendors will receive a nominal cash incentive for each high-efficiency motor sale to encourage their active participation in the program marketing effort.

Incentives for VSDs and other efficiency-enhancing motor sysiem equipment are less common than for motors, but their use in utility programs is growing. The New England Electric System and Niagara Mohawk have achieved more savings in 1992 from their incentive programs for VSDs than for high efficiency motors. BC Hydro has also developed incentives for compressor, pump, and fan system improvements.

\subsection{2 "Package" Incentive Programs}

Many utilities in the U.S. offer so-called "package" or customized incentive programs in which industrial (and often commercial as well) customers receive an incentive for a set of energy-saving measures that they select (often with assistance) and submit to the utility for approval. Motor system efficiency improvement has featured prominently in a number of these programs. Incentives include payments based on energy saved or load reduced in the first year (i.e., $\$ / \mathbf{k W h}$ or $\mathrm{kW}$ saved), rebates based on a percentage of measure cost, payments that reduce the simple payback period to a certain level, cash for the incremental cost of efficient equipment, and low-to-no interest loans. In some cases, utilities combine generic incentives with extensive technical assistance; such an approach is likely to be necessary in developing countries. U.S. utility experience indicates that the most successful efforts combined pre-defined and custom incentiv's.s.

\subsubsection{Loans and Grants}

While loans with zero or below-market interest rates have proven to be much less popular in the U.S. than rebates, they are useful for customers who lack investment capital, as is common in developing countries. In fact, many developing countries have conducted loan programs for industrial energy conservation projects. India sponsors three programs that offer a combination of energy audits and concessional rate loans through its three national development banks. The largest of the programs had financed 122 energy audits and committed \$13 million in loans for 
energy saving equipment as of March, 1990 (Nadel, Geller, and Ledbetter, 1991). The World Bank and other regional development banks have also loaned funds for industrial energy conservation in a variety of countries.

\subsubsection{Tax Incentives}

Governments in many OECD countries have offered tax credits and accelerated depreciation allowances to promote energy-saving investments by industry. From 1978 to 1982, U.S. businesses could take a tax credit equal to $10 \%$ of the capital cost of energy-saving investments. The effectiveness of these policies is questionable, however. However, a study by the Alliance to Save Energy (1983) found that such credits had little impact on energy investments.

In developing countries, taxes can contribute substantially to the cost of a good. For example, the sales tax in Brazil is about $40 \%{ }^{4}$ A few developing countries have implemented preferential tax policies for energy-efficient equipment. The government of Barbados removed sales tax on various energy conservation devices (Thompson, 1985). India also exempts certain energy-saving products from sales tax, but the products were selected with oil consumption, not electricity, in mind (Nadel, Geller, and Ledbetter, 1991). A similar policy lowering or waiving duties on imported energy-efficient motor system equipment where there is not domestic production could also be implemented, although it may be complicated and difficult to administer. For motors, another approach is to base duties or taxes on the input $\mathrm{kW}$ of the moior rather than the price (Anand and Kothari, 1990). This will also provide an added incentive for downsizing, whenever possible.

\subsection{Research, Development and Demonstration (RD\&D) Programs}

RD\&D can play a key role in supporting and advancing the domestic manufacturing of efficient motor system technologies. The Chinese government, for example, supports the development of new designs for industrial end-use equipment at various institutes. RD\&D may also be necessary to adapt technologies transferred from industrialized countries to meet local needs and production pr cesses. Further, consumers may be skeptical of product performance and require demonstration of effectiveness prior to purchase. In Brazil, PROCEL spearheaded RD\&D for motor speed controls and other conservation technologies (mostly unrelated to industrial motors). In some cases, PROCEL studied how to produce energy-efficient goods domestically that would otherwise be available only through imports, or how technologies could be adapted to meet local needs. PROCEL then worked with private manufacturers to market the new product. Key lessons from the PROCEL experience are to plan early to accornmodate a long RD\&D process and to link private and public ventures such that RD\&D in the public sector helps shape production patterns in the private sector.

There are exemptions to this tax, however, for equipment purchased by electric utilities, suppliers of petroleum products, and other public authorities. The same status could be extended to the incremental cost of higherefficiency equipment and justified on the basis of avoided investments in new power supply. 


\subsection{Improving Power Quality}

Reducing large voltage fluctuations and standardizing voltage levels will contribute to higher motor system efficiency since end-users will have less reason to oversize to compensate for large power fluctuations. There are two nodes for improving power quality, though the techniques used to address each are similar: At the supply level, through improvements in the operation of the transmission and distribution system (correcting power factor, improving conductor sizing, controlling voltage levels); and at the plant level, through power factor correction, wire sizing, transformer efficiency gains, and load balancing. In many countries, there is a lack of resources to evaluate overloading and other problems in the transmission and distribution system. Assisting this process should be a high priority. Projects have been initiated to improve the quality of electricity supply in a number of developing countries. Brazil, for example, is setting its nominal voltage levels at 127 and 220 volts, and is also replacing some transformers; the standardization process is expected to last five to ten years. Though policies to correct the power factor in industrial facilities are few, recognition of their importance is growing. A number of countries currently impose penalties on users with poor power factor, and Pakistan is planning a program to help industries correct poor power factor.

\subsection{Issues and Priorities for Developing Countries}

A strong implementing institution is fundamental to the development of a vigorous motor system efficiency program. The policy measures described above will be most successful if implemented as part of a comprehensive package of policies and programs designed to address all aspects of motor system performance. Such a comprehensive plan would require the participation of numerous entities, including utilities, government agencies, lending institutions, trade associations, manufacturers, vendors, and end-users. Building institutional capacity is a vital first step. While the specific design of a motor system efficiency program will be shaped by the unique conditions in each country, all programs will require the empowerment of energy management institutions.

Utilities can play instrumental roles in developing, coordinating, and implementing conservation strategies. Lessons gleaned from the North American experience can help shape similar programs in developing countries and highlight the important role that marketing plays in affecting customer participation rates and overall program success. Developing countries can benefit from the North American experience by selectively applying policies that have proven successful in North America and are appropriate to the unique circumstances of each country.

In a few developing countries, utilities are recognizing that demand-side management can yield important benefits. Overcoming the barriers to conservation will require substantive interaction and the cultivation of working relationships between utilities, distributors, and end-users. Emerging utility programs should work closely with existing energy conservation organizations that have developed close contacts with industry. In many developing countries, such 
organizations have conducted energy audit programs, training courses, technical seminars, and other outreach programs. Since utilities in developing countries generally lack the personnel and experience to conduct energy audits and follow-up assistance, such activities would (at least initially) best be performed by other organizations.

One of the important first steps to promoting motor efficiency is the development of efficiency protocols that provide consistent and accurate results. The testing standards of the U.S. National Electrical Manufacturers' Association and the Canadian Standards Association could serve as models; both provide tight specifications to minimize subjectivity and operator errors. Developing domestic capability to conduct efficiency tests will give local agencies more control over the type and quality of tests used.

Though difficult to assess with the available data, considerable and inexpensive energy savings are expected in developing countries through improved rewinding and O\&M practices. Even in the U.S., O\&M is considered one of the cheapest means of saving electricity in motor systems. Providing guidance on proper O\&M and motor rewinding techniques (including core testing before and after rewinding) should be a high priority. Information and training programs promoting the effective use, maintenance, and repair of motor systems can increase system lifetimes as well as save energy.

Some developing countries may lack the capability to produce devices like high-efficiency motors or VSDs. The larger, more industrially-developed countries may have the capability but not the demand required to sustain domestic production. Utilities can work with industry associations and Ministries of Industry to encourage domestic production of such technologies and can coordinate such efforts with rebate programs or other incentives to increase domestic demand. Developing countries can use existing industrial development channels to promote loans for manufacturers to upgrade or build new production. China, for example, offers low-interest loans and preferential tax treatment to encourage manufacturers to produce new, more-efficient designs. Easing the access of manufacturers to the necessary raw materials is also important.

The provision of financing and other incentives for conservation investments is critical to industrial customers for whom minimizing first costs is a primary consideration. In conjunction with audits and related technical assistance, access to low interest loans and other incentives can reduce the initial cost of conservation investments. Experience in the U.S. indicates that rebates may need to cover a high percentage of the incremental cost of high-efficiency equipment to attract high program participation, and that the most effective programs also involve manufacturers and distributors of high-efficiency equipment. 


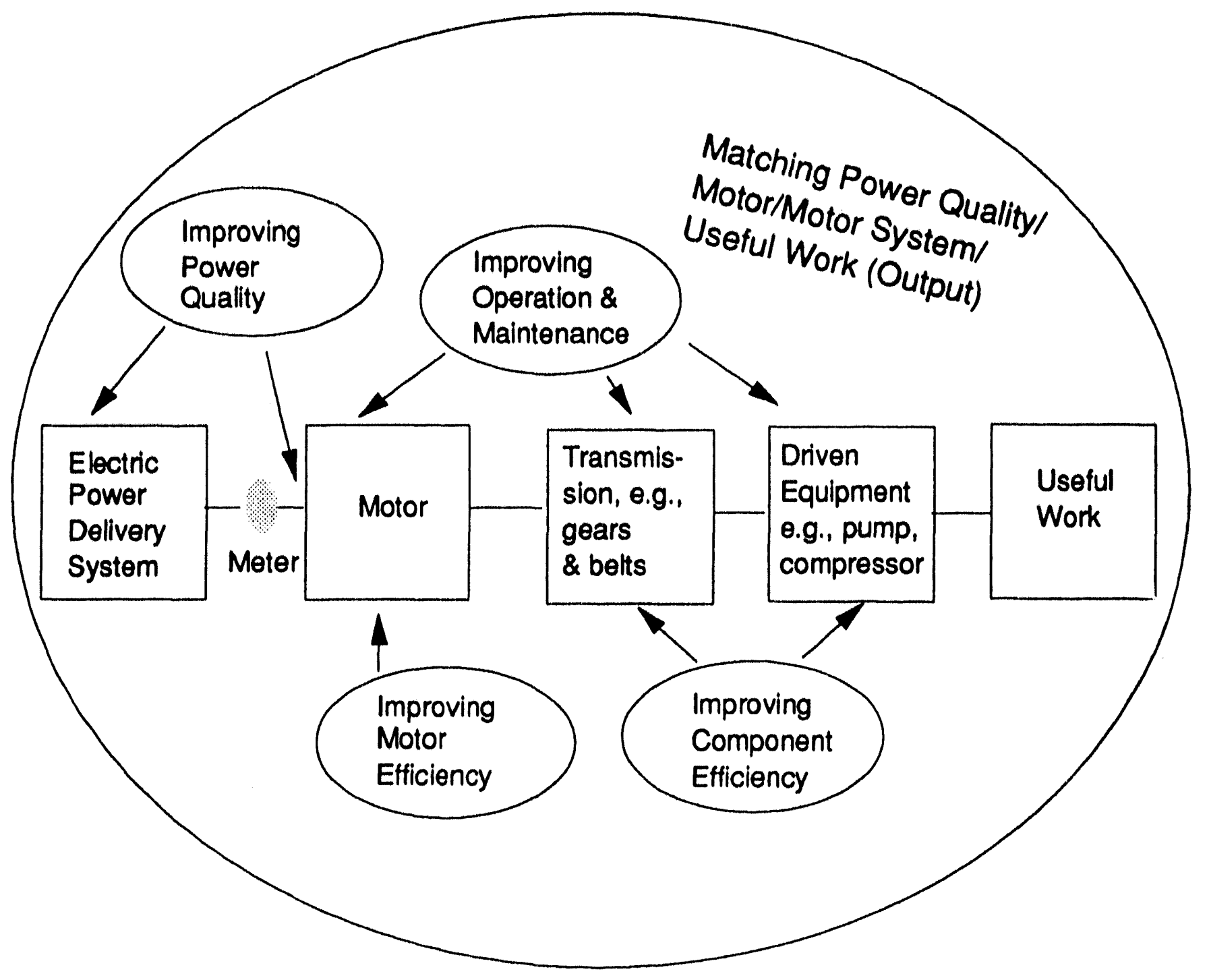

Figure 4.1 Mechanisms for Improving Motor System Efficiency 


\section{Economic Potential for Electricity Savings \\ From Motor System Improvements in India \\ (\% of Projected 2005 All-India Electricity Use)}

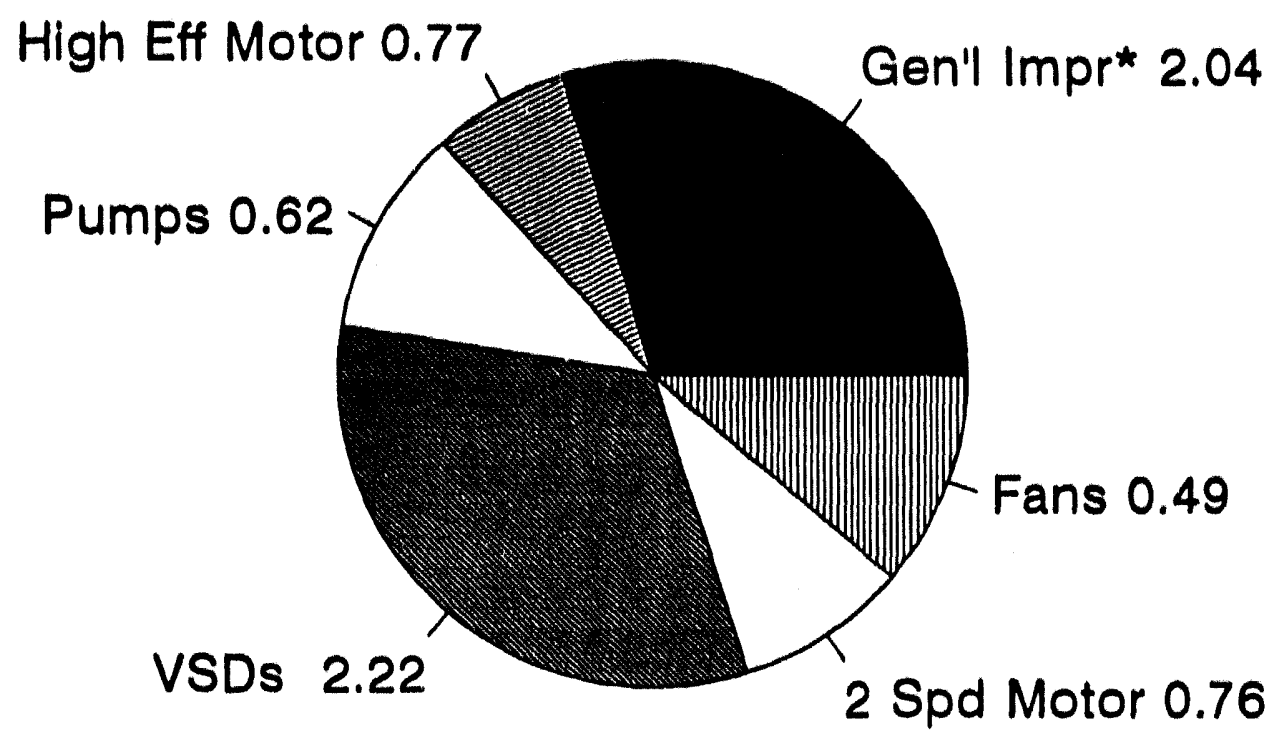

* General improvements include: Improved O\&M; phase balencing; and rewinding and sizing practices. Source: Nadol, Kothari, and Gopinath (1991).

Figure 4.2 


\section{APPENDIX: ECONOMICS OF ELECTRICITY CONSERVATION INVESTMENTS}

There are many ways to assess an energy conservation investment. They all evaluate the capital cost of a conservation measure and the future energy savings that it will bring. The results will vary with the perspective taken (societal or consumer) and the methodology applied. In this report, the value of conservation investments from a societal perspective are expressed primarily in terms of the cost of conserved energy (CCE). The report also evaluates the attractiveness of conservation measures by use of the simple payback expression:

Simple Payback (years) $=$ A / B

where,

$A=$ Incremental Cost of the Conservation Measure (\$).

$B=$ Value of the Expected Annual Energy Saving (\$/year).

For example, if a high-efficiency motor costs $\$ 200$ more than a standard motor and saves $\$ 100$ of electricity each year, then the simple payback is 2 years.

The simple payback concept is a common method used by firms to evaluate the worthiness of a conservation investment, but it has certain limitations. The simple payback assumes constant electricity rates. Moreover, it does not factor in the lifetime of a conservation measure and therefore ignores the value of part of the future savings.

The criteria used by a consumer to assess a conservation measure are very different from those used by an electricity utility to assess long-term investments in power system infrastructure. The CCE allows one to compare the life-cycle cost of a conservation measure to either electricity prices or the costs of supply-side options. It facilitates the development of policies that seek to optimize use of capital from the perspective of society as a whole. The CCE is defined as the discounted annualized cost of implementing an efficiency measure divided by the annual energy saving it provides:

$\operatorname{CCE}(\$ / k W h)=A / B$

where,

$A=$ Incremental Conservation Measure Cost $(\$) *$ Capital Recovery Factor.

$B=$ Annual Energy Saved $(k W h)$.

The incremental conservation measure cost is the difference between the net present value (NPV) cost of the measure and the NPV cost of the alternative. This incremental cost should include the NPV of O\&M costs as well as administrative costs if the investment is made as part of an energy efficiency program.

The capital recovery factor (CRF) equals $d /\left(1-(1+d)^{-n}\right)$, where $d$ is the real discount rate (net of inflation) and $n$ is the lifetime of the conservation measure. The CRF can be seen as the 
fraction paid annually of a loan that is used to finance an efficiency measure, assuming an interest rate equal to the discount rate and a loan term equal to the life of the conservation measure.

The CCE can be compared against the long-run marginal cost (LRMC) of electricity to rate the cost-effectiveness of efficiency measures. A measure with a CCE less than the LRMC would be cost-effective to implement. All else equal, the CCE will be lower (and the investment more attractive) if the annual usage or the lifetime of the equipment increases.

Different discount rates can be used to simulate different costs of capital when evaluating a conservation measure. For example, to evaluate the attractiveness of a conservation measure from the point of view of a small industrial electricity consumer who has a very limited access to capital, a high discount rate can be used in CCE calculations. This technique allows one to use the CCE method, with its longer-term analysis, in place of the simple payback to evaluate a conservation measure from the consumer's perspective. This report, however, uses only the societal perspective in calculating CCEs. The discount rate used by the studies for Brazil, India, and Thailand was $10 \%$, while the Costa Rica study used a slightly higher rate of $12 \%$. 


\section{REFERENCES}

Alliance to Save Energy. 1983. Industrial Investment in Energy Efficiency: Opportunities, Management Practices, and Tax Incentives. Washington, D.C.: Alliance to Save Energy.

Anand, S., 1993. Center for Energy and Environmental Studies, Princeton, NJ, personal communication.

Anand, S., and V.S. Kothari, 1990. "Characterization of Electric Motors in Industry and Energy Conservation Potential in India." New Delhi: Tata Energy Research Insititute.

Baldwin, S. 1989. "Energy-Efficient Electric Motor Drive Systems." In Electricity--Efficient End-Use and New Generation Technologies, and Their Plannine Implications. eds. T. Johansson, B. Bodlund and R. Williams. Lund, Sweden: Lund University Press.

Calhoun, R. 1984. "The Great PG\&E Energy Rebate," In Doine Better: Settine an Asenda for the Second Decade. Washington, D.C.: American Council for an Energy-Efficient Economy.

Captzan, R. 1990. Engenheiro, Reliance Electrica Ltda., Sao Paulo, personal communication with Geller, H. in June, 1990. In Geller, H. 1991. Efficient Electricity Use: A Development Strategy for Brazill. Washington, D.C.: American Council for an Energy-Efficient Economy.

Center for Energy and Environmental Studies and National Productivity Council (Fuel Efficiency Division). 1992. "Electric Motors." Princeton, New Jersey: Princeton University.

Dutt, G. 1991. "End-Use Oriented Energy Strategies for Member Developing Countries." Draft. Manila, Philippines: Asian Development Bank.

Geller, H. 1991. Efficient Electricity Use: A Development Strategy for Brazil. Washington, D.C.: American Council for an Energy-Efficient Economy.

Geller, H., and S. Nadel. 1992. "Consensus National Efficiency Standards for Lamps, Motors, Showerheads and Faucets, and Commercial HVAC Equipment." In Proceedings: 1992 ACEEE Summer Study on Energy Efficiency in Buildings. Washington, D.C.:American Council for an Energy-Efficient Economy.

Fry, T., S. Greenberg, L. Peterson, and P. Rumsey. 1992. "Annex A: Industrial Sector Programs." In "Thailand: Promotion of Electricity Energy Efficiency." International Institute for Energy Conservation. Report prepared for the World Bank and the Global Environment Facility. Bangkok, Thailand: IIEC.

Fryer, L.R., and C. Stone. 1993. "Establishing Baseline Practices in the Industrial and Commercial Motor Market: Findings from the New England Motor Baseline Study." In 
Broceedings: Sixth National DSM Conference. Sponsored by the Electric Power Research Institute. Miami Beach, Florida (March, 1993).

Gustafson, G. and J. Peters. 1987. Process Evaluation of the Indusurial Test Prosmam. Portland, Oregon: Bonneville Power Administration.

Henriques, D. 1989. British Columbia Hydro. Phone conversation with S. Nadel, June, 1989.

Ibanez, P. 1978. "Electromechanical Energy." In Efficient Electricity Use. ed. C. Smith et al. Elmsford, NY: Pergamon Press. 369-409.

International Institute for Energy Conservation. 1993. Information relayed by the Bangkok office of IIEC on $4 / 16 / 1993$ of personal conversations with staff of the Energy Conservation Center of Thailand (ECCT).

Lattore, C., E. Nobre, and J. Burgoa. 1990. "Diagnostico do potencial de conservacao de energia na industria." Anais de $V$ Congresso Brasileiro de Energla 2. COPPE/UFR, Rio de Janeiro, Novembro, pp. 617-626. In Geller, H. 1991. Efficient Electricily Use: A Development Strategy for Brazill. Washington, D.C.: American Council for an Energy-Efficient Economy.

Lewis, P. 1992. "Macro Consumidores de Electricidad: Los Periodos de Retorno por las Inversiones en los Equipos para Majorar el Bajo Factor de Potencia." Nicaragua: Instituto Nicaraguense de Energia.

Lobsosco, O. 1989. "Estado da arte de motores electrico no Brasil e no mundo." Anals de I Seminario de Motores Electricos. Sao Paulo: Associacao Brasileira da Industria Electrica e Electronica, marco. In Geller, H. 1991. Efficient Electricity Use: A Development_Strategy for Brazil. Washington, D.C.: American Council for an Energy-Efficient Economy.

Mayo, B. 1989. Southern California Edison. Phone conversation with Steven Nadel, July.

Miller, P., H. Geller and A.T. de Almeida. 1992. "An Example of Energy Savings in LDCs: Improving Electrical Equipment in Pakistan." Energy 17,10: 969-982.

Miller, P., J. Eto, and H. Geller. 1989. "The Potential for Electricity Conservation in New York State." Albany, N.Y.: State Energy Research and Development Authority.

Montgomery, D. 1989. "Testing Rewinds to Avoid Motor Efficiency Degradation." Energy Engineering 86,3: 24-40.

Nadel et. al. 1991. Energy Efficient Motor Systems. Washington, D.C.: American Council for an Energy-Efficient Economy. 
Nadel, S., H. Geller, and M. Ledbetter. 1991. "A Review of Electricity Conservation Programs for Developing Countries." Washington, D.C.: American Council for an Energy. Efficient Economy.

Nadel, S., V. Kothari, and S. Gopinath. 1991. "Opportunities for Improving End-Use Electricity Efficiency in India." Report prepared for the World Bank. Washington, D.C.: American Council for an Energy-Efficient Economy.

National Productivity Council, 1991. "Report on Review of Power End-Use Efficiencies." New Delhi.

National Productivity Council and the Center for Energy and Environmental Studies. 1993. "Technology Menu for Efficient Energy Use, Motor Drive Systems." New Delhi.

Nelson, D.J. and M.K. Ternes. 1993. "Flipping the Industrial Market: The Move to HighEfficiency Motors." In Broceedines: Sixth National DSM Conference. Sponsored by the Electric Power Research Institute. Miami Beach, Florida (March, 1993).

Office of Technology Assessment. 1992. Eueline Development: Energy Technologief for Developine Countries. OTA-E-516. Washington, D.C.: U.S. Congress.

RCG/Hagler, Bailly, Inc. and Oak Ridge National Laboratory. 1991. "Costa Rica: Power Sector Efficiency Assessment," Report prepared for the Office of Energy, U.S. AID.

Ross, M. 1986. "Trends in the Use of Electricity in Manufacturing," IEEE Technology and Soclery S(1): 18-22. In Office of Technology Assessment. 1992. Eueline Development: Enerry Technologies for Developine Countries, OTA-E-516. Washington, D.C.

Sathaye, J. 1992. "Economics of Improving Efficiency of China's Electricity Supply and Use: Are Efficiency Investments Cost-effective?" Paper presented at the World Bank/Chinese Ministry of Energy Workshop on Coal Utilization and Energy Efficiency in China. April 22-25, 1992, Beijing. Paper revised May 2.5, 1992.

Sens, M. 1989. "Motores de alto rendimento: Uma economica energetica viavel?" Anals de I Seminario de Morores Electricos. Sao Paulo: Associacao Brasileira da Industria Electrica e Electronica, marco. In Geller, H. 1991. Efficient Electricity Use:_A Development Stratery for Brazil. Washington, D.C.: American Council for an Energy-Efficient Economy.

Soares, G. 1993. "Electric Motor Conservation: A Technological View from Brazil," E-notes 3(2). Washington, D.C.: International Institute for Energy Conservation.

Thompson, K. 1985. "Experience Gained from World Bank Energy Conservation Project in Barbados." Paper presented at the Special Workshop on the Rational Use of Energy. CESP/OLADE/UNDP. Sao Paulo, Nov, 24-30. In Nadel, S., H. Geller, and M. Ledbetter. 
1991. "A Review of Electricity Conservation Programs for Developing Countries." Washington, D.C.: American Council for an Energy-Efricient Economy.

Wilke, K. and T. Ikuenobe. 1987. "Guldelines for Implementing an Bnergy-Efficient Motor Retrofit Program." In Broceedinge: 10ih World Bnergy Engineerine Congresy. Allanta: Association of Energy Engineers. 

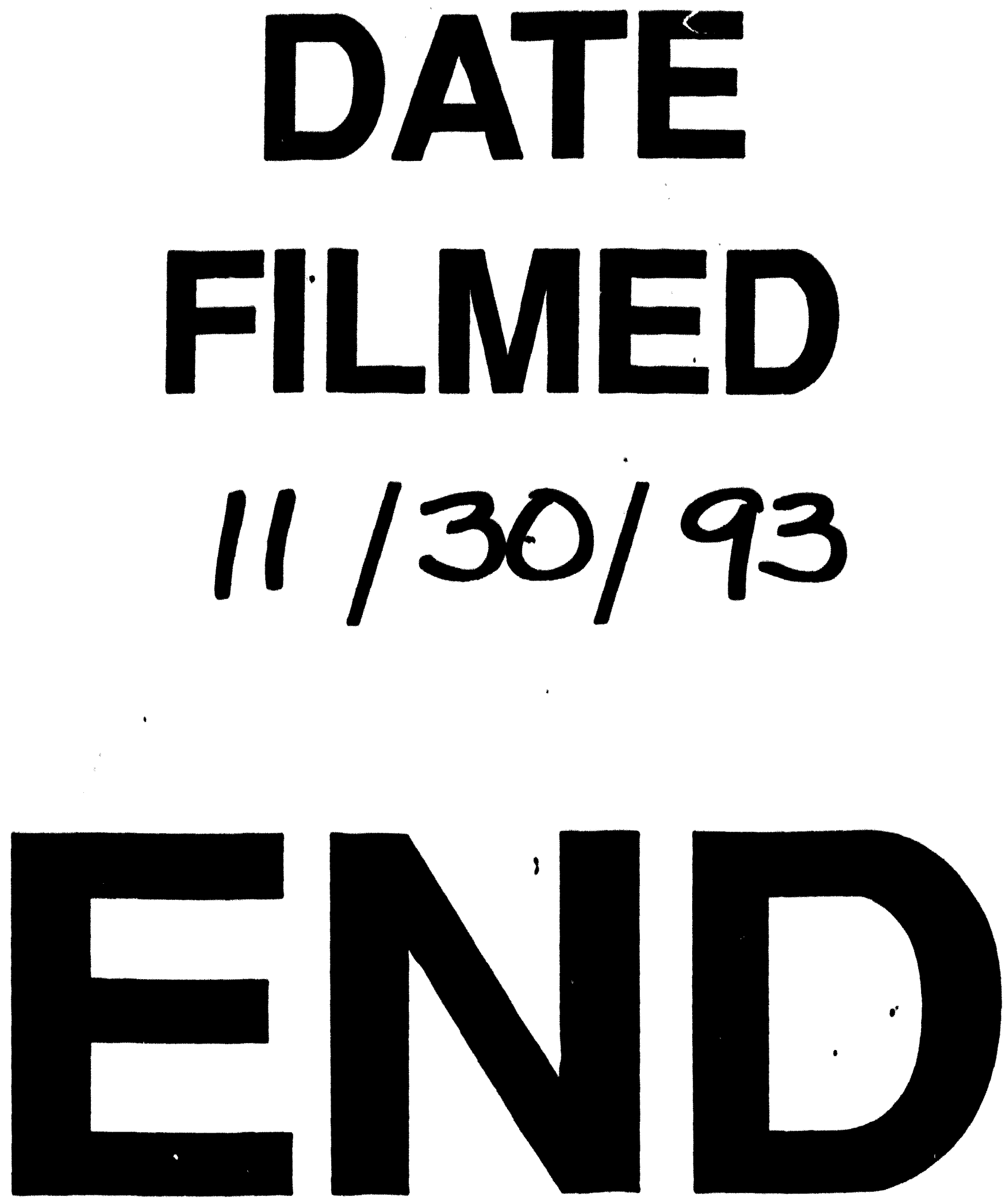


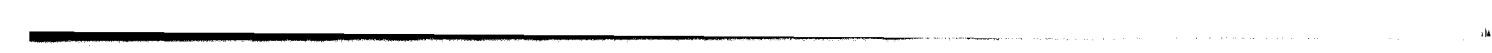

